\title{
IS CYBER AGGRESSION A NEW FORM OF SOCIAL AGGRESSION?: AN EXAMINATION OF THE FREQUENCY AND MOTIVATIONS FOR USING THESE BEHAVIOURS.
}

\author{
by \\ Megan Lamb \\ A thesis submitted to \\ the Faculty of Graduate and Postdoctoral Affairs \\ in partial fulfillment of the requirements for the degree of \\ Master of Arts \\ in \\ Psychology
}

Carleton University
Ottawa, Canada

(C)2014, Megan Lamb 


\begin{abstract}
The current study examined the frequency and motivations for using social aggression and cyber-social aggression against a friend in the past school year. A total of 429 students (females, $\mathrm{n}=227$ ) completed a set of self-report measures. The majority of youth $(86 \%)$ indicated using social aggression against a friend in the past school year, and half $(51 \%)$ of students reported using cyber-social aggression against a friend in the past school year. Further analyses indicated that, girls reported using more socially aggressive behaviours than did boys, particularly with regard to spreading rumours and talking behind a friend's back. However, there were no significant gender differences with respect to using cyber-social aggression. Results of the factor analyses indicated a five factor model for both the Motivations for Social Aggression Scale (Acceptance, Revenge, Amusement, Jealousy, Anonymity), and the Motivations for Cyber-social Aggression Scale (Jealousy, Revenge, Amusement, Social Image, Anonymity). Additionally, the most frequently reported motivations for using social aggression against a friend were Revenge and Acceptance, and Revenge and Amusement for using cyber-social aggression against a friend. Results for the present study have implications for the study of social and cyber-social aggression, and highlight the importance of addressing the motivations for using these behaviours when developing future interventions.
\end{abstract}




\section{Acknowledgements}

I would like to take this opportunity to thank a number of people who have been instrumental to the completion of this project. First, I would like to sincerely thank my supervisor, Dr. Anne Bowker, your constant support, patience, and encouragement was essential to my learning and to the success of this thesis. To my committee members, Dr. Cheryl Harasymchuk and Dr. George Pollard, thank you for providing me with helpful recommendations, and guidance during this process. Cody Holland, Susan Lamb, Ruth Corkum, and the Annapolis Valley Regional School Board, thank you for your help with the data collection; your time and dedication was sincerely appreciated. To my past and present lab members, thank you for your advice and support throughout this process; it has been a pleasure to work closely with you. I would also like to thank the following for participating in this study: Central Kings Rural High School, Berwick and District School, Middleton Regional High School, and Pine Ridge Middle School as well as the students and their parents. Your support and cooperation in this study was crucial to its completion. To my close friends and colleagues, thank you for always listening, understanding, and for your humour. Finally, I want to express my gratitude to my Mom, Dad, Brother and Sister, your unwavering support has been appreciated beyond belief. Without you, this would not have been possible; I love you. Thank you, again, to all who have made this a meaningful, and positive experience. 


\section{Table of Contents}

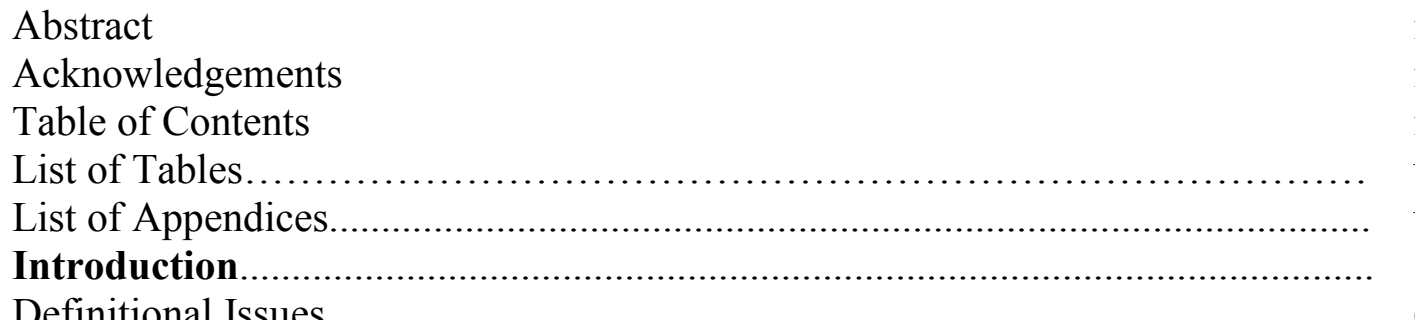

Non-physical forms of aggression................................................... 6

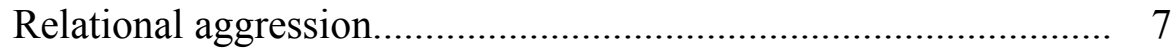

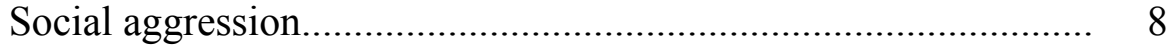

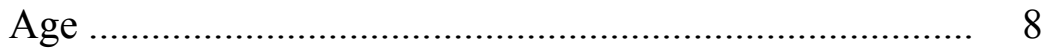

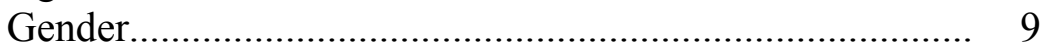

Cyber aggression........................................ 11

Measurement issues..................................................... 14

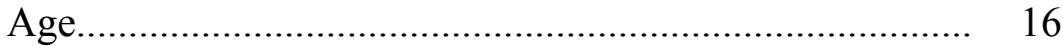

Gender............................................... 18

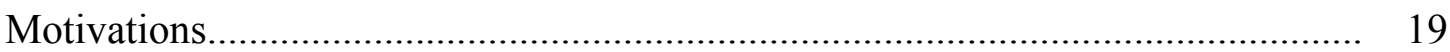

Social aggression....................................................................... 19

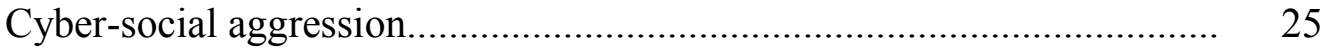

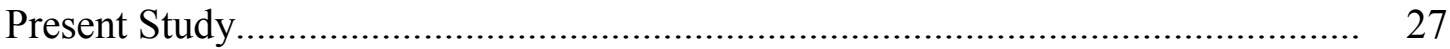

Hypotheses.............................................. 29

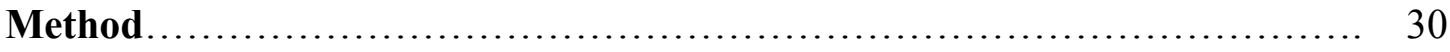

Participants.............................................................. 30

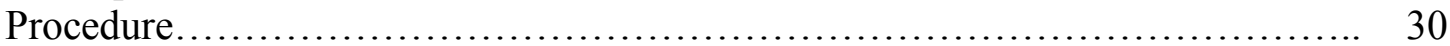

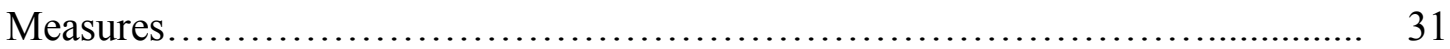

Demographics................................................. 31

Frequency of Socially Aggressive Behaviour....................... 32

Frequency of Cyber-social Aggression.............................. 33

Motivations for Social Aggression....................................... 34

Motivations for Cyber-social Aggression.............................. 34

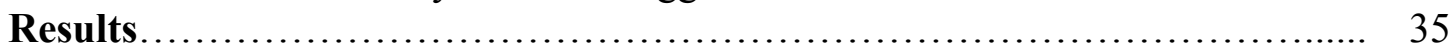

Data Screening ...................................................... 35

Descriptive Statistics............................................... 36

Frequency of social aggression................................ 36

Frequency of cyber-social aggression............................ 37

Gender differences............................................ 38

Development of Motivations for Social Aggression Scale (MSA).............. 39

Development of Motivations for Cyber-social Aggression Scale (MCA)............. 42

Frequency of Motivations.............................................. 45

Exploring Gender Differences for motivation measures...................... 46

Discussion........................................................ 47

Use of social and cyber-social aggressive behaviours...................... 47

Comparison of Motivations.............................................. 49

Motivations for Social Aggression Scale........................... 49 
Motivations for Cyber-social Aggression Scale........................ 50

Measurement issues ............................................... 53

Gender differences............................................... 54

Implications of most endorsed motivations.............................. 55

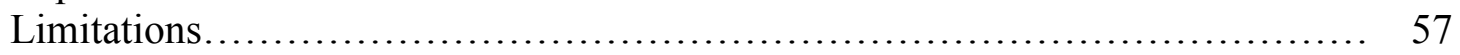

Future Research ...................................................... 58

Conclusion.............................................................. 60

References.............................................................. 62

Tables............................................................. 70

Appendices........................................................ 92 
List of Tables
Table $1 \quad$ Frequency of Grade and Gender of Participants

Table 2 Means, Standard Deviations and Gender Differences for frequency 70 of Social Aggression against a friend

Table 3 Means, Standard Deviations and Gender Differences for frequency 72 of Cyber-social Aggression against a friend

Table 4 Means and Standard Deviations for the Motivations for Social Aggression Scale

Table 5 Factor Loadings for Exploratory Factor Analysis on the Motivations for Social Aggression Scale

Table 6 Fit Indices for Motivations for Social Aggression Scale Exploratory Factor Analysis: Including all 26 items

Table 7 Factor Loadings for Confirmatory Factor Analysis for Motivations for Social Aggression Scale

Table 8 Means and Standard Deviations for the Motivations for Cybersocial Aggression Scale

Table 9 Factor loadings for Exploratory Factor Analysis for Motivations for Cyber-social Aggression Scale

Table 10 Fit Indices for Motivations for Cyber-social Aggression Scale Exploratory Factor Analyses: including all 26 items

Table 11 Factor Loadings for Confirmatory Factor Analysis for Motivations 86 for Cyber-social Aggression Scale

Table 12 Comparison of Motivations for Motivations for Social Aggression 88 Scale and Motivations for Cyber-social Aggression Scale and which factor they loaded on

Table 13 Means, Standard Deviations and Gender Differences for Motivations for Social Aggression and Motivations for Cybersocial Aggression 


\section{List of Appendices}

$\begin{array}{lll}\text { Appendix A: } & \text { Principal Consent Form } & 91\end{array}$

Appendix B: Teacher Consent Form $\quad 94$

Appendix C: Informed Consent Form for Parents 97

$\begin{array}{lll}\text { Appendix D: } & \text { Assent for Children } & 100\end{array}$

Appendix E: Volunteer Script and Information 102

$\begin{array}{lll}\text { Appendix F: } & \text { Debriefing Form } & 106\end{array}$

$\begin{array}{lll}\text { Appendix G: } & \text { Demographics Questionnaire } & 108\end{array}$

Appendix H: $\quad$ Frequency of Social Aggression Scale 113

Appendix I: $\quad$ Frequency of Cyber-social Aggression Scale $\quad 117$

Appendix J: $\quad$ Motivations for Social Aggression Scale 121

Appendix K: Motivations for Cyber-social Aggression Scale $\quad 125$

Appendix L: $\quad$ Reasons for removing Motivations for Social Aggression Scale 129

Appendix M: Reasons for removing Motivations for Cyber-social Aggression $\quad 130$ Scale items 


\section{Is Cyber Aggression a new form of Social Aggression?: An examination of the frequency and motivations for using these behaviours}

Today's youth are more connected to technology than any other generation. In British Columbia, $60 \%$ of youth in grades $5-12$ own a cell phone, and $81 \%$ have access to the Internet at home (Law, Shapka, Domene, \& Gagne, 2012). In fact, a comprehensive Canadian study on the online habits of youth found that Internet "access was almost universal" (Media Awareness Network, 2005). However, just because young people have near constant access to the web, it cannot be assumed that they are fully aware of the risks posed by being online or that they are capable of understanding the challenges of interacting with others online. It is evident that technology plays a large role in the lives

of youth. Unfortunately, being connected to technology puts youth at risk of experiencing cyber aggression. Media Awareness Network found that young Canadians typically do not differentiate between their virtual and real worlds. They do not see the cyber world as a "distinct environment" but simply another medium to engage friends, follow interests, and grow up in today's age (Media Awareness, Network, 2005). Cassidy, Jackson \& Brown, (2009), in a sample of 365 students in grades 6 through 9 in five schools in British Columbia, found that most cyber aggression started at school and then followed the individual home. This means that the individual has no safe place to go, and they are enduring bullying in two aspects of their lives leaving no place to escape.

The number of aggressive acts online has escalated in the past decade (Li, 2010). This is due to the constant accessibility to the Internet and frequency of use among youth. This is of significance because it allows for cyber aggression to escalate quickly and is difficult to stop. Cyber aggression involves harassing, intimidating, or embarrassing 
someone via technology, using such tools as, text messages, social networking sites, and websites. These behaviours are considered to be socially aggressive (Berger, 2007). Social aggression refers to harming another's social status or relationships. It can consist of things like manipulation, teasing, rumours, and mean/rude comments. Cyber aggression involves taking these socially aggressive behaviours and applying them to an online or cyber context (Berger, 2007). This form of social aggression in a cyber environment can include direct or indirect behaviours. For example, cyber aggression can be sending someone an instant message saying, "You are ugly," or starting a rumour about another person on Facebook. The present study examined the frequency of the use of these social and cyber-social aggressive acts and the reasons adolescents report for using them.

To put this issue into context, what follows is a description of three welldocumented high profile cases of cyber aggression that have recently occurred in Canada. These include the death of Ontario teen Jamie Hubley, the death of British Columbia teen Amanda Todd, and the death of Rehtaeh Parsons from Nova Scotia. Jamie Hubley was subjected to cyber aggression regarding his sexual orientation (Burke, 2011). His tormentors began by bullying him at school, which eventually led to online abuse. He was tormented and tortured online to the point where he decided to take his own life. This was a long struggle for him as he had suffered from depression for years in conjunction with the bullying. Amanda Todd's struggle with cyber aggression has been documented extensively over the Internet (Canadian Press, 2012). Her cry for help through a YouTube video (https://www.youtube.com/watch?v=ej7afkypUsc), entitled My Story: Struggling, bullying, suicide and self-harm, which showed her using a series of flash cards to tell of 
her experiences being bullied that she posted before committing suicide, has been seen by millions of viewers. The video post went viral after her death on October 10, 2012, receiving over 1,600,000 views by October 13, 2012. Todd experienced both on-andoffline bullying, which is typical of people experiencing cyber aggression ( $\mathrm{Li}, 2007)$. She was threatened through social networking sites about her past Internet activities including photos that had appeared online. She developed anxiety and depression as a result of recurring incidences of cyber bullying as well as incidences of physical assault by peers, until she felt she could not take it anymore (Canadian Press, 2012). In response to her death, a motion was introduced in the Canadian House of Commons to study the scope of bullying in Canada, and for more funding and support for anti-bullying organizations. This motion was intended to lay the groundwork for a national strategy to prevent bullying (Canadian Press, 2012). A year after the death of Amanda Todd, another high profile case of cyberbullying emerged in the media. Rehtaeh Parsons was cyberbullied for two years before she committed suicide (Banergee, 2013). Photos of her in sexually compromising positions were posted online after she was allegedly raped in 2011. Parsons tried to escape her tormentors but was not able to avoid the cyber aggression. In August 2013, in response to her suicide, Nova Scotia enacted a law allowing victims of cyberbullying to seek protection, including help in identifying anonymous perpetrators, and to sue the individuals or the parents in the case of minors (Banergee, 2013).

Each one of these teenagers experienced social aggression and cyber aggression. They all suffered from the effects of this victimization, and all three youth tried to switch schools and made efforts to escape the bullying. Unfortunately, their attempts to avoid the bullying and move on did not work due to ruthless perpetrators and consistent and 
unavoidable cyber aggression. The adults around them although concerned, were unable to help in any effective way. However, if there were more resources to help victims it is possible that things might have turned out differently. In order for adults to help youth who find themselves in these types of situations, we need to know more about the use of social and cyber aggression. A good place to start would be to understand the underlying motivations that lead youth to perpetrate these kinds of hurtful behaviour.

Although these are three extreme cases that illustrate the severe consequences that can occur as a function of cyber aggression that have grabbed the attention of the media, there are many cases of cyber aggression that go unreported. Currently there is much concern on the part of government, schools, teachers, and parents, in Canada and around the world, about the impact of bullying, in both the physical and cyber environment, on youth. Glen Canning, father of Rehtaeh Parsons, expressed his concern about the magnitude of the problem of cyber aggression with the following quote: "The bullying that goes on today is not a part of growing up, it's not a rite of passage. We've given our kids a communication tool that is like a dragon that's not tamed at all" (Banergee, 2013). The "dragon" referred to here is the use of "technology". It is important that researchers consider the totality of the cyber aggression phenomenon and to determine the characteristics of these harmful relationships and the social dynamics of the peer group that allow these scenarios to play out in such hurtful and harmful ways if we are to aid victims of cyber aggression. The current research study addressed some of the gaps in the literature regarding cyber aggression, especially given the dire consequences and psychological implications of being a cybervictim (Cassidy, Jackson, \& Brown, 2009; Banergee, 2013). 
Limited research has explored the relationship between social and cyber aggression. Therefore, the purpose of this study was to determine the underlying motivations or reasons youth report for their use of social aggression in the physical and cyber environment. Furthermore, it was of interest to establish the frequency of the occurrence of various types of social and cyber-social aggressive behaviours.

A number of researchers have attempted to capture the frequency of cyber aggression (Li, 2008; Hinduja \& Patchin, 2008; Willard, 2004a), however, it has been challenging due to constantly changing technology and the variety of measures that have been used. The present study aimed to build upon the work of past researchers (Willard, 2004a; Hinduja \& Patchin, 2008; Quigley, 2013) to better measure cyber aggression. This was done by reviewing the current measures and modifying them to fit today's youth and to make them more generalizable to current youth experiences. To develop an argument to support the present study, this paper includes: definitional issues of social and cybersocial aggression, what is already known about the frequency and forms of these constructs including age, gender, and measurement issues, as well, as review the literature on motivations for social aggression in both the physical and cyber environment. Prior to extensively reviewing the literature on social aggression and cyber aggression, it is important to define each of these constructs, to gain a better understanding of each, and to determine whether the motivations that underlie the use of these behaviours, in both a physical and cyber context, are similar or different. This will assist in the development of appropriate prevention programs. 


\section{Definitional Issues}

Aggression can be divided into two main forms: physical aggression, that includes acts designed to cause harm to the individual's physical body (Olweus, 1994); and nonphysical form of aggression, referred to as social, relational and/or indirect, which refers to acts intended to cause harm to an individual's relationships or self-esteem (Lagerspetz, Björkqvist, \& Peltonen, 1988; Galen \& Underwood, 1997; Crick \& Gropeter, 1995). The current paper focused specifically on the non-physical forms of aggression, as they are the most common form of aggression used in adolescence (Wang, Iannotti, \& Nasel, 2009).

Non-physical forms of aggression. The research examining the development of relational and social aggression has been complex and confusing due to the many different terms used to describe this phenomena, in particular the terms "relational", and "social" aggression. Although indirect aggression is sometimes lumped into this category of behaviours it is not discussed in the current paper because we were interested in both direct and indirect forms of non-physical aggression. The differences between relational and social aggression are subtle, and some researchers feel that they are more similar than they are different (Vaillancourt, McDougall, Hymel, \& Sunderani, 2011), others argue that they are the same thing (Coyne, Archer, \& Eslea, 2006); while some see them as distinctly different forms of behaviour (Underwood, 2003; Crick \& Grotpeter, 1995). What follows is an examination of the current research exploring these two forms of nonphysical aggression and a comparison of the two in order to clarify the exact nature of the behaviour examined in the current research. 
Relational aggression. In 1995, a term was first introduced to describe nonphysical aggression called "relational aggression” (Crick \& Grotpeter, 1995). These authors identified relationally aggressive behaviours as "behaviours that harm others through damage to relationships or feelings of acceptance, friendships, or group inclusion" (Crick, Casas, \& Ku, 1999, p. 77). Relational aggression can involve the use of both direct and indirect behaviours such as, exclusion, spreading rumours, and denying acceptance into the peer group (Crick \& Gropeter, 1995). A defining factor of relational aggression is that it focuses on damaging relationships (Crick, et al., 1999). For example, telling a friend you no longer want to be friends with him or her in front of a group of people, or maliciously spreading lies about a peer to damage his or her group status. In particular it is about the aggressor manipulating the social environment to his or her advantage (Salmivalli, Kaukiainen, \& Lagerspetz, 2000).

Relational aggression deprives victims of basic social needs including: acceptance, closeness, and friendship (Baumeister \& Leary, 1995). This is concerning because these needs are necessary in order to foster healthy development and wellness in children and youth (Baumeister \& Leary, 1995). Although most youth experience some degree of relational aggression, it is the most highly victimized youth that are of concern. This group of victimized youth is more likely than non-victimized youth to experience social and psychological maladjustment (Crick, Bigbee, \& Howes, 1996).

In contrast to "relational" aggression another type of nonphysical aggression identified in the literature is termed "social aggression." There are many similarities and a few differences identified between the two. 
Social aggression. The term social aggression was originally coined by Cairns, Cairns, Neckerman, Ferguson, \& Gariepy (1989) and expanded upon by Galen and Underwood in 1997. Social aggression is defined as behaviour, "directed toward damaging another's self-esteem, social status, or both, and may take such direct forms as verbal rejection, negative facial expressions or body movement, or more indirect forms, such as slanderous rumours or social exclusion” (Galen \& Underwood, 1997). Some researchers believe that social aggression encompasses those behaviours described as relationally aggressive, such as gossip, breaking confidences, criticizing another behind his or her back, ignoring, social exclusion, embarrassing an individual in public, anonymous mean or rude notes, and practical jokes, but they also include harmful nonverbal behaviours such as an eye roll, the hair flip and the cold shoulder (Archer \& Coyne, 2005).

Currently, most researchers agree that relational aggression can be incorporated into the broader construct described as social aggression (Coyne, et al., 2006). For the purposes of the present study, relational and social aggression were considered overlapping constructs. It is believed that social aggression is a broader construct that includes relationally aggressive behaviours. In the current study, we examined social aggression (including relational acts of aggression as well as the non-verbal body language) as this form of aggression includes a larger array of behaviours that are applicable to a cyber context. Another aim of this research was to clarify debates within the literature on gender and age/grade differences in social aggression in youth.

Age. Social aggression becomes more complex with age (Crick, Nelson, Morales, Cullerton-Sen, Casas, \& Hickman, 2001). Young children tend to use more face-to-face 
and overt forms of relational and social aggression (i.e. "you have to do what I say or you cannot come to my sleepover"; Crick, et al., 2001). Once children reach middle childhood, their use of social aggression becomes more sophisticated and includes direct and indirect acts (i.e. spreading rumours or excluding someone from the peer group). With age, these aggressive acts become more complex and subtle. In particular, once individuals reach adolescence they acquire new relationship dynamics that affect victimization and perpetration. For example, with the development of romantic relationships and more common boy-girl friendships, youth are exposed to more relationally aggressive possibilities (stealing someone else's boyfriend or best friend). It is important to examine the age related differences in social aggression among youth to determine when youth are most at risk for victimization. Specifically, the present study examined youth, as social aggression is most prominent in middle and high school. In the present study, the terms 'youth' and 'adolescent' were used interchangeably, which is consistent with developmental psychology (Gentry \& Campbell, 2002). There is widespread agreement that youth range from 10 to 18 years of age - comprising the period of development between childhood and adult age (Gentry \& Campbell, 2002). In addition to age and grade differences, there is also a gender debate among researchers regarding perpetration of and victimization by social aggression.

Gender. There has been a lot of controversy about possible gender differences in social aggression. The debate surrounds the issue of whether girls experience more social aggression than boys (Crick \& Gropeter, 1995; Crick et al., 1996; Crick et al., 1999; or not (Wang, et al., 2009; Archer, 2004; Card, Stucky, Sawlalani \& Little, 2008). Research focused on observing preschoolers' use of relational aggression (Ostrov \& Keating, 2004) 
has consistently demonstrated gender differences with girls using more acts of relational aggression than boys. In contrast, Archer (2004) in a meta-analysis of 196 studies, across a broad age range and a variety of methodologies (i.e. self-report, observations, peer reports, and teacher reports) found that greater female social aggression was limited to later childhood and adolescence, and varied with the method of measurement. These researchers concluded that the frequency of social aggression is more frequent in girls beginning at 11 years of age and is used increasingly through the teenage years with men catching up in adulthood. In contrast, however, a more recent meta-analyses of 148 studies on child and adolescent social aggression reported small, significant gender differences that the authors described as "trivial" within a real world context (Card et al. 2008). These findings suggest that social aggression may be an important construct to study in both boys' and girls' relationships and requires further examination. The present study has examined gender differences in relation to the frequency and motivations for using social aggression in youth.

In conclusion, the most important consideration for the study of relationally/socially aggressive behaviours, (from here on referred to as "social" aggression), is that the relationship is the focus of harm. In examining non-physical, relationship-based aggression it has recently become apparent that in addition to traditional face-to-face acts of aggression there has been a growing use of technology to harm an individual's relationships and/or self-esteem. Over time, people are being exposed to a growing technological world. This has led to the cyber aggression phenomenon. The majority of cyber aggressive acts reported today are acts intended to cause harm to an individual's social relationships such as, online gossip and rumours, 
criticizing others online, social exclusion via social networking site, and public embarrassment online (Hinduja \& Patchin, 2009; Smith, Mahdavi, Carvalho, Fisher, Russell, \& Tippett, 2008). Thus, it would seem that the next step in research would be to examine cyber aggression as an extension of social aggression.

Cyber aggression. Cyber aggression is becoming a serious global issue (Li, 2008). Cyber aggression involves distributing harmful, hurtful, and humiliating messages, photos, or videos using technological devices. Cyber aggression is defined as, "willful and repeated harm inflicted through the use of computers, cell phones, and other electronic devices" (Patchin \&Hinduja, 2006, p.152). There has been some discussion among researchers regarding the difference between social aggression and cyber aggression. A number of researchers believe that cyber aggression is an extension of social aggression (Smith, et al., 2008; Hinduja \& Patchin, 2009). Li (2007) argued that cyber aggression should be considered an extension of other traditional forms of aggression, due to similar impact and behaviours. Smith and colleagues (2008) expanded on this idea and suggested that cyber aggression is similar to traditional forms of aggression, but it is using a new communication tool. In particular, it was noted that the intention of cyber and social aggression are the same, to cause harm (Li, 2010; Smith, et al., 2008).

Therefore, for purposes of this research, cyber aggression was considered an extension of social aggression. This is because the behaviours associated with cyber aggression reflect those of social aggression. Furthermore, the Internet is being used as a tool to harm a person's social status, self-esteem, or relationships, which mirrors many of the goals of social aggression (Smith, et al., 2008). To better compare these two forms of 
aggression, it is important to examine the behaviours that have been found to comprise acts of cyber aggression.

Researchers have determined five general forms of behaviour that are considered cyber aggression. These include 1) flaming/harassment; 2) denigration; 3) impersonation; 4) outing/trickery; and 5) exclusion/ostracism (Willard, 2004a). Flaming involves the exchanging of messages between two people. These messages are often hostile, aggressive, intimidating, insulting, sarcastic, and include hurtful language (e.g., writing a post on someone's picture on Facebook saying, “you're so fat!”). This behaviour mirrors the socially aggressive behaviour of criticizing someone in the physical world with verbal insults. Harassment is portrayed through repeated harm that could include sending a number of flaming messages. This form of cyber aggression is very popular among youth and others can easily repeat this behaviour by forwarding messages with the click of a button. Harassment can include posting an embarrassing photo of someone online and having a number of other people repost it. This is similar to public embarrassment in a social aggression context.

Denigration is when a perpetrator uses technology to spread hurtful lies about an individual. This is done through portals like social networking sites, text messages, blogs, and websites. This information is often inaccessible to the victim, and very difficult to stop. This form of public embarrassment is particularly harmful because once something is posted on the Internet it can never be removed. The foundation of this cyber aggressive behaviour is socially aggressive. This behaviour is modeled in the physical world through rumours and gossip. 
Impersonation involves pretending to be another person. Due to lack of privacy settings and the plethora of personal information on the Internet, this is very easy to perpetrate, and it is difficult to detect. Impersonation is often used to convince a vulnerable person to give up information about him or herself that the perpetrator can use against him or her. Also, it can be used to torment others and get the victim into trouble. For example, perpetrators may pretend to be someone the victim is close with to get the victim to share private information; or they may pretend to be the victim and post or write inappropriate or embarrassing comments as if he or she were the victim. This form of cyber aggression does not have a direct application in the physical environment. However, it is similar to the use of socially aggressive strategies to turn others against the victim. In addition, impersonation could involve public embarrassment and breaking confidences. Often referred to as "Outing".

Outing someone involves sharing personal information about someone without the person's approval and it is intended to harm the victim. For example, making a status on Facebook about whom a friend has a crush on to humiliate him or her. Unfortunately, this information spreads rapidly on the Internet, which makes the problem escalate quickly. Outing and trickery are often used in unison. Trickery refers to deceiving someone into sharing personal information and then using that information to hurt the individual. This form of cyber aggression would have similar socially aggressive roots as impersonation (e.g. breaking confidence). For example, these behaviours can involve the aggressor obtaining personal and private information about the victim and transmitting it to others. 
Exclusion and ostracism involve removing or excluding someone from a group. With regard to cyber aggression this includes leaving someone out on purpose using technology. This can be done on social networking sites by denying someone entrance to a group, or making the victim aware of an event and explicitly leaving them out. For example, making a Facebook group and not allowing someone to join it, or removing someone as a friend from Facebook to hurt him or her. These behaviours are mostly social in format and are easily transferable to a physical setting.

In comparing these types of cyber acts of aggression to acts of social aggression in the physical realm, it is apparent that the majority of cyber acts of aggression are socially aggressive acts. Thus, for the remainder of this paper, cyber-social aggression was examined. The present study examined the frequency of social aggression in a cyber context. To measure the frequency of cyber-social aggression, it is important to have a valid and reliable measure. To date, researchers have struggled with measuring this construct due to the constant changes in technology, inconsistent measures, and small sample sizes.

Measurement issues. Cyber aggression has been a difficult construct to measure. Researchers have developed a number of instruments over the past decade but are struggling to capture the totality of the construct. To date, there have been three different methodologies employed to attempt to measure cyber aggression in as valid a way as possible. These methods have included: 1 . Giving youth a definition of cyberbullying as a primer, before they report on their own behaviour (e.g. Cyberbullying is willful and repeated harm inflicted through the use of computers, cell phones, and other electronic devices) (Hinduja \& Patchin, 2008; Smith, et al., 2008; Slonje \& Smith, 2008); 2. Using 
the word "cyberbully" as a descriptor and leaving it up to youth to report on what they believe to be "cyberbullying" (e.g. Have you ever cyberbullied?) (Li, 2006); and 3. Asking about behaviours associated with cyberbullying without using the term or defining it (e.g. How often have you insulted or hurt other students by mean texts during the last two months) (Gradinger, et al., 2009; Ybarra \& Mitchell, 2007; Wolak, Mitchell, \& Finkelhor, 2006). Each of these techniques has strengths and weaknesses.

Hinduja and Patchin's approach (2008) where they provide a definition of cyberbullying before youth complete a survey about their experiences with this form of behaviour can be problematic if the participant has experienced cyber aggression that does not fit into the definition provided. In addition, it is possible that participants will misinterpret the definition, which will yield inaccurate results (Ybarra, Boyd, Korchmaros, \& Oppenheim, 2012). Using the word "bully" when collecting data from youth may deter them from reporting honestly because of social desirability. Some youth may want to portray a certain image when reporting their experiences. Also, some participants may not want to admit to using the described behaviours because they do not want to be labelled a bully or they fear the possible repercussions. In addition, solely using the word "bully" assumes that the researcher and participants have the same interpretation of this word. Variations in understanding the term "bully" could lead to diverse results.

As an alternative to providing a definition of cyberbully, some researchers have used behavioural lists to try and capture the frequency of cyber aggressive behaviours. Using behavioural experiences when collecting information about cyber aggression may not yield accurate results because it is difficult to encompass all possible experiences of 
cyber aggression in one measure or questionnaire. Also, due to rapid changes in technology, measures may become outdated quickly. Therefore, it is necessary to develop universal experiences that can be applied to all different forms of technology.

Researchers have found that when using a behavioural list of cyberbullying experiences, without providing a definition for "bullying" or using the word "bully" in the survey, higher prevalence rates are reported (Ybarra, et al., 2012). Specifically, online victimization for being cyberbullied more than once a month, was found to increase from $7 \%$ to $12 \%$ when researchers did not include a definition of "bullying" or the word "bully" in the measure (Ybarra, et al., 2012). Thus, it is clear that to accurately measure the frequency of youth experiences with cyber aggression it is important to ask about the specific behaviours that are being used and experienced, without prefacing the questions with a definition of "bullying". It is clear that there are a number of steps to take to accurately measure cyber aggression. Specifically, it is important to stay on top of current technology. Therefore, the present study aimed to add to what has previously been asked about cyber aggression and develop a current measure of the frequency of cyber-social aggression. Upon examining the frequency of these behaviours, researchers are also interested in the gender and age dynamics of these youth. There has been much debate among researchers about whether these differences exist.

Age. The majority of the research regarding age effects and the use of cyber aggression, is inconsistent. For example, the Health Behaviour in School-aged children study in the United States surveyed 7,508 students in grades 6-10 (Wang, et al., 2009) about perpetration and victimization across physical, verbal, relational, and cyber aggression. They found that cyber aggression peaked in grades 7 and 8 (Wang, et al., 
2009), possibly due to the number of changes and transitions youth are going through at this age. This was further substantiated by Tokunaga, (2010). In a study of cybervictimization, researchers interviewed 16 cybervictims between the ages of 15 and 17 about how victims perceive online attacks and the harm of these behaviours (Sevcikova, Smahel, \& Otavova, 2012). They found that cyber aggression decreased in later adolescence (Sevcikova, et al., 2012). This finding is consistent with the findings of Smith and colleagues (2008) in a sample of 11-16 year olds.

In contrast, Ybarra \& Mitchell used data from the Youth Internet Safety Survey in the United States. This included 1,501 interviews with youth ages 10-17 and their parents about victimization and perpetration of online harassment. They found that there were no significant age differences in perpetration or victimization of cyber aggression (Ybarra \& Mitchell, 2004; Williams \& Guerra, 2007; Slonje \& Smith, 2008). Thus, it is clear that age differences continue to be conflicting across samples and methodologies. These differences may be due to measurement tools and procedures. For example, Ybarra \& Mitchell (2004) may have not found differences because parents were present during the interviews. Thus the children may have been hesitant to answer truthfully. Due to the lack of consistency across research studies, the present study examined cyber aggression in a sample of youth between grades 6 and 12, because it has been reported by a number of researchers that adolescence is a peak period for involvement in cyber aggression (Wang, et al., 2009). Therefore, the present study applied this knowledge to cyber-social aggression. In addition to age, there is also debate among researchers about whether gender differences exist in who perpetrates, and is the target, of cyber aggressive acts. 
Gender. Gender differences in the use of cyber-based aggression are not clear. One researcher in a study of 7,508 youth in grades 6-10 found that boys were more likely than girls to be perpetrators of cyber aggression (Wang, et al., 2009). This study used self-report to measure physical, verbal, relational, and cyber aggressive behaviours in youth. These findings were consistent with a study conducted by Li (2006), using selfreport measurement of cyberbullying with 264 youth in grades 7-9 in Canada. Wang and colleagues (2009) also found that while boys were more likely to perpetrate cyber aggression, girls were more likely to be victims of cyber aggression. This is also consistent with a study of 533 youth, ages 11-16 examining the relationship between cyberbullying and Internet use (Smith, et al., 2008).

However, in a study of 1150 students, ages 10-15, about measuring and defining cyberbullying, researchers found no gender differences in use of cyber aggression (Gradinger, Strohmeier, \& Spiel, 2010; Slonje \& Smith, 2008). In other studies, gender differences in cyber aggressive behaviours are found inconsistently (Slonje \& Smith, 2008; Smith, et al., 2008; Ybarra \& Mitchell, 2004). Specifically, Slonje \& Smith (2008), found no gender differences when examining four ways to cyberbully (text message, email, phone call, picture/video clip) among youth. Furthermore, Smith and colleagues (2008), did not find any significant gender differences in perpetrating cyberbullying in a sample of youth ages 11-16. Given these inconsistencies the present study has examined gender differences in cyber-social aggression and perpetration among youth in the hopes of clarifying this area of research.

An additional, critical, factor that may impact perpetration of cyber acts of aggression, are the underlying motivations or reasons for using these behaviours. To date, 
there has only been qualitative research (Varjas, et al., 2010) done on the reasons for perpetrating cyber aggression. The present study aimed to determine the reasons youth report for choosing to harm each other using social aggression, in both a real world and cyber context. In order to do this, it is necessary to review what is already known about the motivations or reasons for using social aggression and cyber aggression.

\section{Motivations}

After reviewing the current literature regarding definitions, demographic differences, and measurement of social and cyber-social aggression, it is important to consider why youth use social and cyber-social aggressive behaviours. The present study examined youth's reasons for using social aggression in both a physical and a cyber context.

Youth report using socially aggressive behaviours for the following reasons: revenge, control and self-interest. These reasons are consistent with the motivations children reported for using physically aggressive behaviours (Delveaux \& Daniels, 2000). Researchers have found that children report using these socially aggressive strategies to avoid trouble from adults (because they are often covert and difficult to detect) and to keep positive relationships with the rest of the peer group (Delveaux \& Daniels, 2000). Thus, it is clear that youth use social aggression to avoid trouble from adults and peers, and to damage the victim's self-esteem, social status, and relationships. The present study has referred to these goals/reasons for using social aggression as "motivations."

Social aggression. There have been five studies to date that have examined motivations or social goals related to the use of socially aggressive behaviours. These include: Delveaux \& Daniels (2000); Owens, Slee, \& Shute (2000), Reynolds \& Repetti 
(2010), Pronk \& Zimmer-Gembeck (2012) and Quigley (2013). Delveaux and Daniels (2000) in a study of 273 boys and girls in grades 4-6, examined differences in motivations between those who reported they would use social versus physical strategies of aggression, given the threat of an interloper to a friendship. They found that the three most endorsed reasons for using social aggression were the same as those reported for physical aggression; revenge, self-interest, and social control. In contrast to physical aggression, however, they found that those who endorsed the use of social aggression were more concerned about not getting caught by adults, and were more concerned about maintaining a relationship with the rest of the peer group.

Owens, Shute, \& Slee (2000a) examined the reasons girls reported for their use of socially aggressive strategies. They conducted 45-minute interviews with small focus groups of 15-16 year old girls in South Australia ( $\mathrm{N}=54$ girls in groups of 6-8) about their reasons for using social aggression. They identified a number of reasons for the use of social aggression including; to alleviate boredom and create excitement in their lives, to seek attention from peers, to be included in the peer group or to belong to a desirable peer group, for self-protection from potential social attacks by peers, because they were jealous over same or opposite sex relationships, and to seek revenge. They found amusement to be one of the most common motivators for using social aggression, while friendship and group processes were the second most commonly reported reason.

For more than a decade, further research in motivations waned. However in the last few years there has been a resurgence of interest in the underlying motivations reported for the use of socially aggressive strategies. In 2010, Reynolds and Repetti conducted a quantitative study examining the reasons reported by 114 American girls in 
grades nine and ten for using social aggression. The following motivations for using social aggression were measured quantitatively through a self-report instrument:

amusement, social control, and revenge. The most endorsed reasons reported among girls for their use of social aggression included: to get back at the target; because they thought their friends did not like the target; it seemed like a fun thing to do at the time; it helped them get closer to other girls; and they thought the target was doing something bad to them. Interestingly, these are the same motivators that had been reported earlier (Owens et al., 2000a; Delveaux \& Daniels, 2000).

Due to the early interest in "girls' aggression", especially in the media, there has been a tendency to ignore boys' use of social aggression and especially their motivations for using socially aggressive strategies. To address this gap in the literature, in 2010, Pronk and Zimmer-Gembeck interviewed both Australian boys and girls about their use of social aggression. Children 11-13 years old were given vignettes describing socially aggressive interactions and were asked why someone would use social aggression, and what he or she would hope to achieve. Three general themes emerged: social dynamics, aggressor characteristics, and victim characteristics.

The goal of social dynamics was described as a desire to maintain or increase one's social standing. This included having power over someone, attaining social dominance, and using attention-seeking behaviours. Aggressor characteristics referred to the aggressor's emotional states such as, jealousy, boredom, anger, and friendship insecurity. Thus the desired outcome for using social aggression was reported to be to compensate for negative internal feelings by increasing positive self-feelings. Victim characteristics were described as characteristics that were associated with the victim's 
personality or traits that were connected to the victim being disliked or victimized. For example, lack of social appeal or excessive emotionality was seen as legitimate reasons to victimize an individual using socially aggressive strategies. The use of these strategies to facilitate peer acceptance, even when used against a friend was a common theme. Social attacks were reported to be an effective way to gain popularity within the dyadic, group, and grade level in both boys and girls (Pronk \& Zimmer-Gembeck, 2010).

Overall, Pronk \& Zimmer-Gembeck, (2010) found that the specific motivations of those who use social aggression were similar for both boys and girls. These included: jealousy, revenge, creating excitement to alleviate boredom, anger, fluctuating moods, and friendship insecurity. Boys reported power as a motivator more often than did girls. In addition, boys used socially aggressive behaviours to exclude boys who did not display stereotypical masculine traits or to exude power, whereas girls used social aggression to manipulate friendships and gain social status. In this study it appeared that both girls and boys experienced, and perpetuated, social aggression.

Quigley (2013) has conducted the most recent research on motivations for using social aggression. This included a sample of 151 boys and girls in grades 6-8 from the Ottawa area. Quigley developed a measure of Motivations for Social Aggression (MSA) across contexts for this study that was built on five theoretical categories that were developed into motivations: friendship insecurity (jealousy), social dominance (revenge), social dynamics (acceptance), amusement (amusement), and sociocultural rules (social image). These categories were constructed from the earlier qualitative and quantitative research (Pronk \& Zimmer-Gembeck, 2010; Owens et al., 2000a; Delveaux \& Daniels, 2000). 
Quigley found that girls endorsed social aggression against an interloper that threatened a friendship. This is referred to as friendship insecurity. Owens et al. (2000) explained it as a social attack in anticipation of a social attack (i.e. I did something to her before she could do something to me). Friendship insecurity has been one justification for social aggression through protection (Quigley, 2013; Pronk \& Zimmer-Gembeck, 2010; Reynolds \& Repetti, 2010; Owens et al., 2000).

Social dominance can involve a desire for power or popularity, socially isolating a peer, or belonging to the "right" group. A desire for power is key to social dominance (Vaillancourt, McDougall, Hymel, \& Sunderani, 2010). Many youth justify using social aggression through the motivator of social dominance because they feel that it is okay to use revenge to restore balance through damaging or threatening social status. This behaviour is often driven by a desire for power and control over a group (Reynolds \& Repetti, 2010).

Social dynamics involves using social aggression to achieve group acceptance (Quigley, 2013). For example, Reynolds and Repetti (2010), found that if perpetrators felt that their friends did not like the victim, than being socially aggressive toward the victim would help the perpetrator get closer to the group. In addition, inclusion in the group was supported as an acceptable reason to use social aggression among youth (Owens, et al., 2000).

Amusement as a motivator included using social aggression against a friend to create excitement and alleviate boredom (Quigley, 2013; Owens et al., 2000). A number of youth used social aggression to entertain themselves because they lacked hobbies and 
activities (Owens, et al., 2000). Amusement as a motivator was more common among boys (Quigley, 2013).

Sociocultural rules and expectations was the final motivator found by Quigley (2013). This category was derived from past research on girls' motivations for social aggression. For example, girls are socialized to contain their anger and express it in a covert manner because "girls are supposed to be nice." Also, girls are supposed to play it “cool” (Pronk \& Zimmer Gembeck, 2010). Primarily, youth endorsed sociocultural rules and expectations as a motivator to use social aggression to avoid detection and maintain a positive relationship with the rest of the peer group (Delveaux \& Daniels, 2000).

Thus, this small body of research on the underlying motivations for the use of socially aggressive strategies in the physical environment has consistently reported a few core motivations. These have been summarized by Quigley (2013) to include five basic motivations: acceptance, amusement, jealousy, revenge, and social image. However, as the use of technology continues to increase among youth the question that comes to mind is "What are the motivations for social aggression in the cyber realm? Are they similar to those that precipitate the use of social aggression in the physical environment or do they differ? Due to the rising use of technology, people are more frequently experiencing social aggression on the Internet. In particular, individuals are using computers, cell phones, gaming devices, etc to harm other people's relationships and gain social status. Thus it is important to examine the cyber-social aggression phenomenon to determine if it is different from social aggression in the physical realm. The present study proposed to compare social aggression and cyber-social aggression to determine similarities and differences in order to best approach prevention and intervention for both forms of 
perpetration of social aggression. In order to be able to do this, an examination of what is known to date about the motivations for cyber aggression, follows.

Cyber-social aggression. A few studies have been conducted to examine the motives for the use of cyberbullying in general. For example, Li (2010), in a Canadian sample of 269 students in grades $7-12$, found that $45 \%$ of youth believe that youth use cyber aggression because they feel insecure, angry, jealous, bored, or they have family issues. Shockingly, $64 \%$ of youth reported that cyber aggression happens for fun, and 1 in 5 thought cyber aggression was a 'cool' behaviour (Li, 2010). These findings are consistent with Reynolds and Repetti's (2010) most endorsed reasons for using social aggression (e.g. amusement, revenge, acceptance) in the physical environment.

Varjas and colleagues (2010), examined motivations for cyber aggression in an ethnically diverse sample of 20 high school students, 15-19 years old. Semi-structured interviews were conducted with participants. They found that $90 \%$ of youth used a cell phone, $100 \%$ had a computer with Internet at home, and $90 \%$ had a profile/account with a social networking site. Varjas and colleagues divided the motivations for cyber aggression into two types: internal and external. Internal motivations included things that were internal to the individual, such as redirecting feelings, revenge, making yourself feel better, boredom, instigation, protection, jealousy, seeking approval, trying a new persona, and anonymity/disinhibition. External reasons to perpetrate cyber aggression included it was fun, non-consequential, non-confrontational, and because they felt the victim was physically different. These were all common reasons for cyber aggression reported by perpetrators. 
Upon comparing these findings regarding the motivations for cyber aggression and those reported for the use of socially aggressive strategies in the physical world researchers have found many similarities. For example, revenge, boredom, jealousy, approval, protection, and amusement/fun were all common motivations reported by youth for using both social (Quigley, 2013; Reynolds \& Repetti, 2010; Pronk \& ZimmerGembeck, 2010) and cyber aggression (Varjas,Talley, Meyers, Parris, \& Cutts, 2010). For example, the motivations found through quantitative analyses for social aggression identified five factors: 1. Acceptance, 2. Revenge, 3. Amusement, 4. Jealousy, and 5. Social Image (Quigley, 2013); while the motivations found for cyber aggression determined through qualitative analyses included: redirecting feelings, revenge, making yourself feel better, boredom, instigation, protection, jealousy, seeking approval, trying a new persona, and anonymity/disinhibition, it was fun, non-consequential, nonconfrontational (Varjas et al., 2010). Many of these motivations for cyber aggression fall under the factors identified by Quigley (2013) for the motivations for social aggression. Thus, it appears appropriate to apply what is known about the frequency and motivations for the use of socially aggressive in the physical world to the use of socially aggressive strategies in the cyber world.

It is evident that both social aggression and cyber aggression have similar goals because both aim to harm another's self-esteem, relationships, and social status (Quigley, 2013; Reynolds \& Repetti, 2010; Varjas, et al., 2010). This knowledge leads to the questions: Are social aggression and cyber-social aggression different in frequency? Do these two forms of behaviour have similar underlying motivations? The present study quantitatively measured both social and cyber-social aggression and the motivations 
reported for the use of each. The research to date on cyber aggression has examined this form of aggression in a general way and has not looked at the specifics of the behaviours perpetrated. In order to achieve a better understanding of the behaviours that are used to aggress or bully via technology in the current study, it was proposed that only social acts of cyber aggression be examined and that the underlying motivations for these behaviours be compared to the motivations for using these same socially aggressive behaviours in the physical world. The biggest challenge in conducting this study was the measurement issue. Since there was not a current measure of motivations for cyber-social aggression the most up-to-date and best developed instrument currently used to assess the motivations for the use of social aggression (Quigley, 2013) was modified for the purposes of the present study.

\section{Present Study}

The present study is an examination of social and cyber-social aggression specifically looking at the frequency of perpetration of these behaviours, as well as the underlying motivations for the use of these forms of aggressive behaviours across adolescence (grade 6-12). It is clear that there are a large number of youth who are experiencing cyber-social aggression (Smith et al., 2008). It is important to further examine this vulnerable population because cyber aggression may influence the psychological, emotional, and physical well being of youth (Smith et al., 2008). Most anti-bullying programs in schools today have been designed to address traditional bullying and aggression but few protocols and procedures are in place to defend against social and cyber-social aggression. Therefore, it is important to begin determining what are the most frequent forms of social and cyber-social aggression among youth, as well as 
to examine the motivations for both these forms of social aggression in order to develop effective prevention strategies and programs.

The present study examined aggression in friendships, as this area of research is limited. Research on aggression in friendship groups has found that approximately $95 \%$ of youth reported using social aggression against a friend in their friendship group at least once in the past year (Quigley, 2013); and a study conducted in central Canada found that approximately $7 \%$ of boys and girls reported high levels of relational victimization from the person they considered their best friend (as cited in Daniels, Quigley, Menard \& Spence, 2010). Since aggression is often underreported, it is important to examine why youth feel it is okay to use such high levels of aggression against their friends. It is also important to have a clear definition of friendship. Quigley (2013) defined a friend as "someone you consider a friend who hangs out in your group of friends". The present study expanded this definition to make things clearer for participants (see Appendix E). In particular a friend was defined as "anyone in his or her peer group. It can be anyone from a close or best friend to someone who they may hang out with but may not particularly like."

The present study addressed the gaps in the current literature regarding social and cyber-social aggression. An adequate sample size was used in order to facilitate finding group results that are generalizable to the larger population. In addition, the current study examined both boys and girls in order to determine if gender differences were present in behaviours and motivations. This is interesting as most studies that have researched motivations have been gender specific. Finally, the present study is one of the few to quantitatively study the motivations for socially aggressive acts and one of the first to 
quantitatively study the motivations for cyber-social aggression across adolescents. The research questions that were asked include: "What is the frequency of perpetration of social aggression and cyber-social aggression in adolescents as a function of gender?";

"Do motivations for perpetration of social aggression and cyber aggression differ?"; and "What are the most common motivations for using social aggression and cyber-social aggression?".

Hypotheses. There is little research about the motivations for using cyber-social aggression. Particularly, researchers have not determined an appropriate quantitative measure to determine the motivations for cyber-social aggression. Therefore the present study used the information from qualitative interviews about the motivations for cyber aggression and what is known about the motivations for social aggression to determine an appropriate measure of cyber-social aggression (Varjas, et al., 2010; Quigley, 2013). It was hypothesized that the motivations for cyber-social aggression would be similar to that of social aggression: amusement, acceptance, revenge, jealousy, social image, with the addition of anonymity - due to the large amount of research around cyber aggression and its appeal due to anonymity. In addition, it was predicted that revenge and acceptance would be the most highly endorsed motivations for using both social and cyber-social aggression in both boys and girls (Quigley, 2013).

The current research suggests that gender differences in social and cyber-social aggression are conflicting and inconsistent (Card et al., 2008; Gradinger, et al., 2009). In addition, there is a breadth of research to suggest that both boys and girls use social and cyber-social aggression at similar rates. It was expected that boys and girls would report engaging in similar frequencies of both social and cyber-social aggression. It was 
hypothesized that there would be gender differences with regard to the most endorsed motivations for using social aggression and cyber-social aggression (Quigley, 2013). That is, girls would be more likely to endorse aggression for revenge purposes, whereas boys would be more likely to use aggression for amusement reasons.

\section{Method}

\section{Participants}

Participants included 429 students (females, $n=227$ ), in Grades 6-12 at two middle schools and two high schools in rural Nova Scotia. The majority of youth were in middle school grades 6-9 (see Table 1). Due to the relatively restricted age range of participants, further analyses did not include age as a variable.

\section{Procedure}

Permission was obtained from the Annapolis Valley Regional School Board Superintendent and the Carleton Psychology Ethics Committee. The principals of each school gave their permission for their school to participate (Appendix A). In addition, teachers gave classroom time to students who were given permission to participate (Appendix B). The parent or guardian of each student gave written consent (Appendix C). In addition, children gave verbal assent, or written consent (depending on his or her age) after being informed about the purpose and their role in the study. It was communicated to students that participation is voluntary, and they have the right to discontinue at any time without penalty. Confidentiality and anonymity were explained in child friendly language (Appendix D).

Once consent was given, the researchers visited classrooms to collect data. Questionnaires were administered to students as a group in their classrooms. In order to 
ensure confidentiality each participant was assigned an ID number that appeared on their survey so that there is no way to identify a specific student. Students were spread out around the classroom so that neither teachers or other students could see an individual's answers. They were given a piece of paper to cover their answers to further ensure confidentiality. Most classrooms participated at the same time in order to minimize school disruptions. All volunteers completed the Annapolis Valley Regional School Board police checks for working with vulnerable populations. Before administering questionnaires, volunteers briefly introduced themselves and described the purpose of the study. Specifically, they addressed the definition of a friend, and issues relating to confidentiality and anonymity (Appendix E). After the questionnaires were completed, participants were given a written and verbal debriefing (Appendix F) about the purpose of the study and were provided with a list of local helpful resources for those individuals who may desire help in the area of social aggression either in a physical or cyber environment.

\section{Measures}

Four questionnaires were handed out in one package: Frequency of Social Aggression, Frequency of Cyber Aggression, Motivations for Social Aggression, and Motivations for Cyber Aggression. The questionnaires took approximately 45 minutes to complete.

Demographics. Basic demographic data was collected for each participant. This included: age, grade level, gender, ethnicity, time spent on the Internet, access to/use of electronic devices, and time spent on social media (Appendix G). 
Frequency of Socially Aggressive Behaviour (FSAB). This scale measured socially aggressive behaviours including, gossip and rumours, exclusion, and negative non-verbal body language that individuals use to cause social harm in the physical environment. This measure is an extension and replication of two measures originally developed by Reynolds and Repetti (2010) and Galen \& Underwood (1997), and modified by Quigley (2013) to represent the construct of social aggression (see Appendix H). The FSAB examined the frequency with which youth report using socially aggressive behaviours. Participants were asked to identify the types of socially aggressive behaviours they have engaged in, and have been a victim of, since school started in the fall.

To create an overall score for the frequency of social aggression against a friend, all items on the scale were summed and averaged. This scale consists of 15 items. For the present study the scale was slightly modified to have youth report frequency of social aggression since school started in the fall (8 month span) rather than the past year. This was done to get a more precise measure of the frequency of these behaviours. This was of interest because Nova Scotia recently passed a law against cyberbullying. In addition, the rating scale was changed to reflect actual frequency of use rather than more general frequency as a function of time (i.e. from (0 (never), 1 (about once a term), 2 (about once a month), 3 (a few times a month), 4 (about once a week), 5 (many times a week)) was changed to (0 (never), 1 (once or twice), 2 (3 or 4 times), 3 (5 or 6 times), 4 (6-8 times), 5 (more than 8 times)). This allowed for a more precise measurement of the frequency of social aggression among participants because it is examining a smaller time window for participants to report in. In addition, changing the scale to a more quantitative answer 
format made it easier for researchers, educators, parents, and students to interpret. A validation study done by Quigley (2013) found the Cronbach's alpha for this scale to be .92 .

Frequency of Cyber-social Aggression. Given that to date there are no validated measures of motivations for cyber-based social aggression, the Frequency of Social Aggression scale developed by Quigley (2013) was modified to make it applicable to socially aggressive strategies perpetrated via technology. Specifically, the socially aggressive behaviours were adapted to an online environment. Examples from Willard (2004) forms of cyber aggression were used to get an idea of which cyber-social aggressive behaviours are the most frequent. Specifically, an effort was made to make sure that each of Willard's 5 categories (1) flaming/harassment; 2) denigration; 3) impersonation; 4) outing/trickery; and 5) exclusion/ostracism) was represented in this measure. For example, to ask about Impersonation a question asks "How often since school started in the fall have you pretended to be a friend online to embarrass him or her." This was done to cover all known behaviours associated with social aggression in a cyber environment. The final survey includes 15 questions related to the perpetration of cybersocial aggression, and 15 questions addressing victimization of cyber-social aggression during the past eight months (e.g. How often since school started in the fall have you spread rumours or wrote something negative about a friend online?) (See Appendix I). Questions were rated on a 6-point Likert scale ranging from 0 (Never) to 5 (More than 8 times). To create an overall score for the frequency of cyber social aggression against a friend, all items on the scale were summed and averaged. 
Motivations for Social Aggression. This scale was recently validated and developed by Quigley (2013). It included 28 items that participants rated on a scale from: 1 (Completely disagree) to 5 (Totally Agree) (Appendix J). Students were asked to think of a particular event with a friend since school started in the fall (past 8 months), when they used social aggression. They provided a brief description of the event, and then answered questions about why they behaved this way. Quigley (2013) determined 5 main factors for using social aggression through Exploratory Factor Analyses: Acceptance (e.g. Ijust wanted to be accepted by the group); Amusement (e.g. I was bored); Jealousy (e.g. I was jealous of him/her) Revenge (e.g. I was angry about something and wanted to put him/her in his/her place) and Social Image (e.g. I thought he/she was too emotional). Items were averaged for each of these factors, with higher scores indicating more endorsement of an explanation for using social aggression. Three items were added to this scale to address the possible external motivations (anonymity) for cyber aggression identified by Varjas and colleagues (2010). These were added to keep consistency among the two motivation measures. Given the additional items and the fact that the participants in the present study were older than Quigley (2013), an exploratory factor analysis was conducted on this measure (see Results section for more details)

Motivations for Cyber-social Aggression. Given the lack of a validated measure of the motives for cyber-social aggression modifications were made to Quigley's (2013) measure of motivation for social aggression to make it applicable to a cyber-social environment. We know through qualitative interviews that the motivations for cyber aggression reported by adolescents are similar to that of the current measure of Motivations for Social Aggression (Varjas, et al., 2010; Quigley, 2013). The list of 
socially aggressive behaviours was modified to be specific to the cyber environment rather than the physical environment.

Youth were asked to recall a specific time when they used cyber-social aggression against a friend in the past 8 months (Since school started in the fall) and describe it in a short paragraph. Participants were then asked why they used cyber social aggression in this situation. At this time, participants were asked to rate how much they agreed with each of the statements provided about why they used cyber-social aggression. A total of 28 possible motivations for using cyber social aggression were included in this survey (Appendix K). Each statement was rated on a 5-point Likert scale ranging from 1 (Completely disagree) to 5 (Totally Agree).

\section{Results}

\section{Data Screening}

The data was first screened for univariate and multivariate outliers, and then the Motivations for Social Aggression measure and the Motivations for Cyber-social Aggression measure were modified and examined. First, univariate outliers were examined, followed by outliers in total scores for the variables. Upon examining the outliers, it was found that none were of concern. All items were retained as the trimmed mean for each value was marginally different from the original mean, indicating that the extreme scores are not distorting the data. Univariate outliers were left outside of range as they are the individuals that we were concerned with (e.g., individuals with more aggression experiences), and bringing them within range would only offer marginally different results. It is important to note that outlier removal does not contribute significantly to variance in the distributions of a given measurement, but it could increase 
effect size in overall findings (Orr, Sackett, \& Dubois, 1991).

Normality of the data was explored but was not a major concern. All variables were skewed in the same direction (positive), as there were low reports of cyber and social aggression. None of these values were outside of the expected range, thus transformations would offer only marginal improvements (Tabachnick \& Fidell, 2007).

\section{Descriptive Statistics}

The main purpose of the present study was to examine motivations for bullying among middle and high school students. Of particular interest were the potential differences between social aggression (harming another's social status or relationships) and cyber-social aggression (harassing, intimidating, or embarrassing someone via technology, using such tools as, text messages, social networking sites, and websites).

Frequency of social aggression. To measure the frequency of social aggression, fifteen items assessed how often participants had used a range of socially aggressive behaviours over the past school year against a friend. Items on this measure were taken from Quigley (2013) who based the questionnaire on two studies: Galen \& Underwood, 1997; Reynolds \& Repetti, 2010.

Frequencies for each form of social aggression against a friend were examined ((0) never; (1) once or twice; (2) 3 or 4 times; (3) 5 or 6 times; (4) 6-8 times; (5) more than 8 times). The majority of youth $(86 \%)$ reported using social aggression against a friend since school started in the fall ( 8 month span). See Table 2 for means and standard deviations for each item. Rolled eyes at a friend(10) was the most frequent socially aggressive behaviour in the past school year, with the average frequency between 1 (once or twice) and 2 (three or four times). All other behaviours were used, on average, less 
than once or twice a term, with exclusionary behaviours being the least used by participants. Following Quigley (2013), items were summed and averaged, to create an average social aggression score $(M=.50, S D=.60 ;$ Cronbach's alpha $=.89)$, with higher scores indicating a higher frequency of social aggression displayed towards friends.

Frequency of cyber-social aggression. To measure the frequency of cyber-social aggression used against a friend, fifteen items were used. These items were developed from the previous social aggression measure and through a literature review on the most common cyber-social aggressive behaviours among youth (Varjas, et al., 2010; Willard, 2004). The main objective of this measure was to encompass all possible cyber-social aggressive behaviours used among youth.

Frequencies for each form of cyber-social aggression were examined. Approximately $51 \%$ of students reported using cyber-social aggression against a friend since school started in the fall. See Table 3 for means and standard deviations for each item. Given a friend the silent treatment online by ignoring his or her messages and Deliberately ignored a friend's emails, texts, Facebook posts etc. in order to exclude, alienate, or embarrass him or her online were the most frequently reported behaviours by youth. All other behaviours were reported infrequently by participants, and Deceiving friends online and Sharing friends' secrets online were the least frequently reported. Items were summed and averaged, to create an average cyber-bullying score $(M=.22$, $S D=.44$; Cronbach's alpha $=.91)$, with higher scores indicating a higher incidence of using cyber-social aggression towards friends. Although the mean score is higher for social aggression $(M=.50)$ than for cyber-social aggression $(M=.22)$, the correlation between these two measures was $.79(p<.001)$, suggesting that individuals who use more 
social aggression with friends, also tend to use more cyber-social aggression.

Gender differences. Of interest was whether boys and girls differed with respect to their use of social and cyber-social aggression. To begin, an ANOVA was run comparing average scores for Social Aggression. Girls reported using more social aggression against a friend $(M=.61, S D=.63)$ than boys did $(M=.49, S D=.51)$, $F(1,329)=4.04, p=.045$. To further examine this gender difference, a MANOVA was calculated to examine the type of socially aggressive acts used by males and females. The dependent variables were the 15 socially aggressive behaviours, described in the frequency scale. Results revealed a significant effect for gender, $F(14,315)=1.73, p$ $=.049$, Wilks' $\lambda=.93$. An examination of the univariate tests showed that there were significant differences as a function of gender for the following items: girls reported Spread rumours or said something negative about a friend who wasn't there at the time $(M=.83, S D=1.20)$ more often than boys $\operatorname{did}(M=.54, S D=.87), F(1,328)=5.98, p$ $=.015$. In addition, girls reported Talked behind a friend's back $(M=1.24, S D=1.38)$ more often than boys $\operatorname{did}(M=.90, S D=1.16), F(1,328)=5.72, p=.017$. Furthermore, girls reported Gave a friend the "silent treatment" $(M=.95, S D=1.07)$ more often than boys $\operatorname{did}(M=.70, S D=1.06), F(1,328)=4.64, p=.032$. Lastly, girls reported Glared or stared at a guy/girl meanly $(M=.69, S D=1.13)$ more often than boys did $(M=.45, S D$ $=.86), F(1,328)=4.66, p=.032$.

Next, an ANOVA was calculated to examine gender differences between total cyber-social aggression scores. Boys and girls did not differ significantly with respect to their use of cyber-social aggression (Girls, $M=.38$, $S D=.57$; Boys , $M=.32, S D=.38$ ). In summary, students reported using social aggression against a friend more often 
than cyber-social aggression, although average scores were below 1 (indicating less than once or twice in the past year). With regard to gender, girls reported using more socially aggressive behaviours than did boys, particularly with regard to spreading rumours and talking behind a friend's back. However, there were no significant gender differences with respect to using cyber-social aggression.

\section{Development of Motivations for Social Aggression Scale (MSA)}

The Motivations for Social Aggression scale (MSA), was originally developed by Quigley (2013) and was designed as a self-report measure to assess an individual's motivations for using social aggression against a friend. This scale included 23 items with the following factors: Amusement (e.g., I was bored), Acceptance (e.g., I just wanted to be accepted by the group), Revenge (e.g., I was trying to get back at him/her for something he/she did that made me mad), Jealousy (e.g., I was jealous of him or her), and Social Image (e.g., I thought he or she wasn't cool). The present scale is an expansion and replication of the measure developed by Quigley (2013). The MSA is identical for boys and girls. In the present study, four additional items were added; including the one item removed by Quigley due to multicollinearity and an additional three items were added to assess the idea of "anonymity" as a factor (e.g. I knew I would not get in trouble). Each statement was rated on a 5-point Likert scale ranging from 1 (Completely disagree) to 5 (Totally Agree). Means and standard deviations for each item in the MSA (Table 4) were reported.

An exploratory factor analysis (EFA) was conducted to determine the most appropriate factor structure for this scale, because of the added items and the fact that the present sample included adolescents, not young adults. It was expected that the modified 
scale would contain six factors: Amusement, Acceptance, Revenge, Jealousy, Social Image, and Anonymity. The modified version of the MSA was administered to 429 students in grades 6-12 from rural Nova Scotia. One hundred and eighty-nine students reported using social aggression against a friend in the last school year (approximately an 8 month range). Only participants who reported using social aggression against a friend since school started in the fall were included in subsequent analyses. Although $86 \%$ of youth had initially had reported using social aggression against a friend, when asked to identify a specific incident and report their motivations, only $40 \%$ of the sample responded affirmatively.

To begin, bivariate correlations between items were conducted to see if there was an issue with local dependence. A cut-off of 0.8 was used (Tabachnick \& Fidell, 2007). Items 10 and 11 were significantly highly correlated $(r=.89)$. Therefore, one item had to be removed to ensure no pairs of items were too highly correlated, suggesting redundancy. Item 10 was removed as it was less clearly communicated to participants. It was important to remove this item to ensure that the correct amount of variance was accounted for in the measure.

The remaining 26 items were factor analyzed with maximum likelihood extraction and geomin rotation (Table 5). One to six factors were examined to see which model best fit the present scale. Factor loadings of at least 0.35 on one, but not more than one factor, were considered good indicators of the underlying concept. Five items failed to reach these criteria and were removed from further analyses (see Appendix L). While it was expected that a six factor model would be the best fit, results revealed that, a five-factor model appeared to provide the best fit. There were six factors with eigenvalues greater 
than 1 , cumulatively accounting for $61.3 \%$ of the variance in the full item set.

Examination of the scree plot suggested a five or six factor solution. Only 21 items loaded unambiguously onto one of the five factors (Amusement, Acceptance, Revenge, Jealousy, Anonymity).

In addition, this model produced adequate fit indices. The Comparative Fit Index (CFI) was 0.867, which indicates a good fit (Bentler, 1990); and the Tucker Lewis Index (TLI) was 0.789 , which indicates a moderately good fit. To further support a five-factor model, the standardized root mean-squared value (SRMR), a measure of the standardized difference between the observed correlations and predicted correlations, was .043. Values less than .05 indicate good fit. Table 6 shows fit indices for models with three- to sixfactor solutions.

After removing items of concern, a confirmatory factor analysis (CFA) was performed with the recommended five factor structure (see Table 7) for the remaining 21 items. The fit indices for the MSA were adequate. The CFI was .904, which indicates a good fit (Bentler, 1990); and the TLI was .887, which also indicates good fit. To further support this model, the SRMR value of .062 was adequate.

Factors resulting from the CFA were labelled: Acceptance (e.g., I just wanted to be accepted by the group), Amusement (e.g., It seemed like a fun thing to do), Revenge (e.g., I wanted to get back at her for something she did that make me mad), Jealousy (e.g., I was jealous of him), and Anonymity (e.g., I thought it was unlikely that I would get caught) (see Table 7). Four of the five factors corresponded to those identified in Quigley's (2013) measure. Amusement, Revenge, and Jealousy were all essentially the same factors. Acceptance included several items from the Social Image factor (e.g., I 
wanted to get my point across to him/her but stay "looking nice" to the rest of my friends) which was not identified as a distinct factor in the present study. Finally, the Anonymity factor was new, as these items were added to the questionnaire for the present study (e.g., I thought it was unlikely that I would get caught).

\section{Development of Motivations for Cyber-social aggression Scale (MCA)}

The MCA is a new scale, based on the MSA scale developed by Quigley (2013). The MCA is a self-report measure to assess an individual's motivations for using cybersocial aggression against a friend. It is important to remember the definition of cybersocial aggression for the present study: Cyber aggression involves distributing harmful, hurtful, and humiliating messages, photos, or videos using technological devices (Hinduja \& Patchin, 2008). Cyber-social aggression is thus considered an extension of social aggression because many of the cyber aggressive acts reported are acts intended to cause harm to an individual's social relationships such as, online gossip and rumours, and criticizing others online.

It was expected that the motivations for using cyber aggression would be similar to those used for social aggression, thus the same six factors were originally predicted (Amusement, Acceptance, Jealousy, Revenge, Social Image and Anonymity). As with the MSA, the MCA is identical for boys and girls. Means and standard deviations for each item in the MCA (Table 8) were reported. Twenty-seven items were examined to determine the most common motivations for cyber-social aggression among youth. An exploratory factor analysis (EFA) was used to determine the most appropriate factor structure for this scale because it is a new scale. It was expected that the MCA would contain six factors. One hundred and fifteen students reported using cyber-social 
aggression against a friend in the last school year (approximately an 8 month range).

Only participants who reported using cyber-social aggression against a friend since school started in the fall were included in subsequent analyses. Although $51 \%$ of youth had initially had reported using cyber aggression against a friend, when asked to identify a specific incident and report their motivations, only $25 \%$ of the sample responded affirmatively.

To begin, bivariate correlations between items were conducted to see if there was an issue with local dependence. Items 9 and 12 were significantly highly correlated $(r$ $=.84)$. Thus, one of the two items had to be removed to ensure no pairs of items were to highly correlated, suggesting redundancy. Item 12 was removed as it was more general, and not as easily understood by participants. The remaining 26 items were factor analyzed with maximum likelihood extraction and geomin rotation (Table 9). One to six factors models were examined to see which model best fit the present scale. Factor loadings of at least 0.35 on one, but not more than one factor were considered good indicators of the underlying concept. Four items failed to reach these criteria and were removed from further analyses (see Appendix M).

There were six factors with eigenvalues greater than 1, cumulatively accounting for $71.6 \%$ of the variance in the full item set. However, even though a six factor structure was predicted, no items had significant loadings on the sixth factor. Thus, a five factor structure was determined to be the best fit for the present data, accounting for $67.6 \%$ of the variance. The Comparative Fit Index (CFI) was 0.871, which indicates a good fit (Bentler, 1990); The Tucker Lewis Index (TLI) was 0.795, which indicates a moderately good fit. To further sustain the five-factor model, the standardized root mean-squared 
value (SRMR), a measure of the standardized difference between the observed correlations and predicted correlations, was .041 . Values less than .05 indicate good fit. Table 10 shows fit indices for models with three- to six-factor solutions.

The factor loadings for the full 26 items in the 5-factor structure are presented in Table 9. However, only 22 items loaded unambiguously onto one of the five factors (Jealousy, Acceptance, Revenge, Social image, Anonymity). After removing items of concern, a confirmatory factor analysis (CFA) was performed with the recommended five factor structure. The fit indices for the MCA were adequate. The CFI was .877, which indicates a good fit (Bentler, 1990); and the TLI was .857, which also indicates good fit. To further support this model, the SRMR value of .075 was adequate. The factor loadings for the CFA are presented in Table 11.

Many of the items loaded on the same factors as in the MSA. Three of the factors were almost identical for both measures: Revenge, Amusement, and Anonymity. As mentioned with the MSA: Revenge included items that indicated using cyber-social aggression as a form of revenge or wanting to get back at a friend; Amusement included items that indicated using cyber-social aggression because he or she was bored, or thought it was a fun thing to do; Anonymity involved using cyber-social aggression because he or she knew he or she would not get into trouble, and no one would find out. To better visualize the comparison between the factor structures of the MSA and MCA, please see Table 12 .

The final two factors, Jealousy and Social Image, differed slightly from the MSA measure. Jealousy included items indicating using cyber-social aggression because one was jealous of a peer's relationship or material things (e.g., I was jealous of him or her) 
as well as trying to advance one's social status (e.g. I wanted to be accepted by the group or I thought it would get me closer to a guy/girl I liked). These latter items loaded on the Acceptance factor on the MSA measure - a factor that did not emerge in the MCA factor analysis. Their grouping on the same factor for cyber social aggression highlights the fact that both jealousy and acceptance emphasize relationships and the importance of gaining status through relationships.

Social Image included items indicating using cyber-social aggression to maintain one's social image. This factor included five items (e.g., I wanted to belong to the right group or I thought he or she was not cool). This factor was not present in the MSA but was similar to Quigley's social image factor.

In summary, results of the factor analyses reveal similar, but not identical, factor structures for these two motivational measures. Specifically, the motivations of Revenge (e.g., I was trying to get back at him/her for something he/she did that made me mad), Amusement (e.g., I was bored) and Anonymity (e.g. I thought it was unlikely that anyone would know who did it ) were consistent across both scales. However, concern for one's Social Image was only a factor with respect to cyber-social aggression and reasons relating to Acceptance (e.g., I wanted to be accepted by the group) did not represent a separate factor for cyber-social aggression, rather some of the Acceptance items loaded on the Jealousy factor in the MCA.

\section{Frequency of Motivations}

Factor scores for each of the five subscales, for both the MSA and MCA, were calculated, with higher scores indicating greater endorsement of a specific motivation (see Table 13). All Cronbach's alphas for the MSA and MCA subscales were within 
acceptable range.

The most frequently reported motivations among boys and girls for using social aggression against a friend were Revenge $(M=2.83, S D=1.52)$, and Acceptance $(M$ $=1.59, S D=.77)$. These scores indicate that those who used social aggression against a friend somewhat to moderately agree that is was for revenge purposes, and it was slightly to somewhat because they wanted to be accepted. The most frequently reported motivations for using cyber-social aggression were Revenge $(M=2.72, S D=1.49)$ and Amusement $(M=1.72, S D=1.10)$. These scores indicate that those who use cyber-social aggression against a friend somewhat to moderately agree that is was for Revenge purposes, and slightly to somewhat agree that it was for Amusement.

\section{Exploring Gender Differences for motivation measures}

To examine gender differences in these motivations, two MANOVAs were performed on the factor scores. The dependent variables were each motivation (Acceptance, Revenge, Amusement, Jealousy, Anonymity). Results revealed a significant effect for gender, $F(5,128)=4.23, p=.001$, Wilks' $\lambda=.86$. An examination of the univariate tests showed that significant differences existed as a function of gender for the following motivations: girls used social aggression to gain Acceptance $(M=1.74, S D$ $=.87)$ more frequently than did boys $(M=1.36, S D=.53), F(1,134)=8.23, p=.005$. In addition, girls reported using social aggression due to Jealousy $(M=1.61, S D=.99)$ more frequently than boys $\operatorname{did}(M=1.18, S D=.54), F(1,134)=8.34, p=.004$. There were no significant gender differences in relation to the motivations for using cyber-social aggression. 


\section{Discussion}

The purpose of the present study was to determine the frequency of perpetrating social and cyber-social aggression, and the motivations for adolescents' use of social and cyber-social aggression. The increase of cyberbullying among youth is a major concern among researchers and educators. The internet has become another avenue for youth to have social relationships, good and bad. Therefore, it is important that researchers determine the frequency and motivations behind these aggressive acts. It was hypothesized that participants would report using social aggression and cyber-social aggression to a similar extent. It was predicted that these two constructs would produce measures with similar motivations and that there would be gender differences with regard to the endorsement of these motivations. Lastly, it was thought that Revenge and Acceptance would be the most highly endorsed motivations for social aggression and cyber-social aggression.

This discussion will highlight the findings with respect to how frequently these types of aggression are used, or reportedly used, the reasons for using them, and how this varies across social aggression and cyber-social aggression. It will also highlight the gender differences that were found and discuss the implications of the findings for intervention programs. Following this, the limitations of the current study will be discussed, along with future recommendations.

\section{Use of social and cyber-social aggressive behaviours}

Contrary to expectations, participants did not report equal use of social and cybersocial aggression. A larger proportion of youth admitted to using social aggression against a friend, as opposed to cyber aggression. Although this is not surprising due to 
past research that indicates a higher frequency of social aggression than cyber, it was thought that these two forms of aggression would be used to a similar extent. It is possible that youth did not report as much cyber-social aggression as it is less acceptable with all of the recent cyber bullying cases in Canada. Furthermore, it is possible that the large amount of attention given to bullying leads to low reports and makes this construct more difficult to study. The present study considered this and tried to talk about bullying as a normal thing that youth do, to try and get more honest reports. However, this was not as successful as we had hoped. It is possible that this is why many researchers have only collected qualitative data on bullying because of the comfort and rapport that can be built in an interview setting. To improve self-reports of bullying, it may be necessary to have a small introduction or activity regarding the frequency of bullying, to make youth more comfortable sharing their own experiences.

Consistent with past research, the present study found inconsistencies with reports of social and cyber-social aggression. For example, although $86 \%$ of youth were willing to admit to using social 'in general', when asked to describe a specific incident with a friend, many fewer (40\%) were willing to do so. Frequencies were even lower for the use of cyber aggression. Due to the 'social taboo' around admitting to bullying another person, reports of using aggression against a friend are often low (Hinduja \& Patchin, 2008; Ybarra, et al., 2012). The current study tried to combine all suggestions from researchers to minimize measurement issues by providing a definition that did not include the word 'bully,' providing a list of behaviours that participants may have engaged in, and giving an 'other' option for participants to expand on the frequency and motivations for using these types of behaviours (Li, 2007; Hinduja \& Patchin, 2008; Ybarra, et al., 
2012). Unfortunately, reports of social and cyber-social aggression were still inconsistent. It is likely that youth had an easier time reporting the frequency of aggressive acts 'in general' because they only had to report how often they used aggression against a friend; whereas the motivation measure had youth report a specific time when they were aggressive toward a friend and then talk about why it happened. This type of question is likely to result in more negative feelings about one's self because of the detail required to answer the questionnaire. Therefore, it is possible that youth did not feel as comfortable explaining a specific event because it led to shame or embarrassment.

\section{Comparison of Motivations}

Motivations for Social Aggression Scale. The present study found that the motivations for social aggression and cyber-social aggression are more similar then they are different. The majority of items and factors were consistent with that of Quigley (2013). The results of the present study suggest that there are five main motivations or reasons for using social aggression (Acceptance, Revenge, Amusement, Jealousy, Anonymity). This was largely consistent with previous work with the addition of a new factor of Anonymity. Anonymity did come out as a prominent factor in the present study that adds to the idea of using social aggression against a friend because it is unlikely one will be caught and it is more inconspicuous way to aggress against one's friends.

These findings tell us that youth are using social aggression against their friends for reasons including, acceptance, revenge, amusement, jealousy, and anonymity. These findings are consistent with Quigley (2013) and Reynolds and Repetti's (2010) most endorsed reasons for using social aggression (e.g. amusement, revenge, acceptance). It is important that researchers further examine these reasons for using social aggression 
against a friend because most youth feel that their actions are justified. It is possible that assertiveness training would be beneficial so that youth can express their feelings with friends rather than aggressing against them. That is, in certain cases, an adolescent may feel uncomfortable telling a friend directly that they have done something to hurt her feelings, and so she may turn to a less direct way (by telling another friend, or posting something rude on Facebook) to express her upset.

Motivations for Cyber-social Aggression Scale. The main purpose of this study was to determine an adequate measure of the motivations for using cyber-social aggression against a friend. Since it was speculated that cyber-social aggression is an extension of social aggression in a cyber environment, it was thought that adolescents' reasons for using cyber-social aggression would be similar to their reasons for using social aggression. It is important that researchers determine the motivations of cybersocial aggression due to the growing rates of cyberbullying among youth. The majority of cyber aggressive acts reported today are socially aggressive in nature and youth are using the internet as a portal to express these aggressive feelings, making it critical to understand the motivations for this form of aggression (Hinduja \& Patchin, 2009; Smith, Mahdavi, Carvalho, Fisher, Russell, \& Tippett, 2008).

The present study found that the MCA produced a very similar factor structure to the MSA. Amusement, Revenge, Social Image, and Anonymity all came out as prominent factors in the MCA. Unexpectedly, Acceptance and Jealousy were present in a combined factor. This could be due to the similarities between the items in these two factors, or it could be because of the small sample size. Further examination of this factor made it clear that the items may have been too awkwardly worded and caused confusion 
among participants. In addition, it can be argued that jealousy and acceptance have similar roots because both factors are related to attaining a more desirable relationship (friend or romantic).

It is important to address the presence of Anonymity as a reason for using aggression against a friend in both scales. Although Anonymity was a factor in both measures, it is known that cyberbullying is even more anonymous than social aggression due to the fact that if an individual is socially aggressive toward someone, the victim generally knows who the perpetrator is, even if he/she cannot do anything about it, but with cyber aggression it is possible that the victim has no idea who the perpetrator is. This is one of the most unsettling things about cyber aggression especially since youth are reporting it as a main reason for using this harmful behaviour. It is possible that interventions need to address internet awareness and to explain how damaging it can be for someone to be bullied online. Someone posting anonymous comments on an on-line discussion board, for example, may have no idea what the consequences are of this behaviour for the victim, as they are not present to see the victim's reaction.

Furthermore, Social Image as a factor was only present in the MCA. Is it possible that this is also related to the accessibility and effortlessness of cyber aggression? Social Image is about maintaining one's social image and showing dominance over a 'less cool' individual. It makes sense that this came out as a clear factor in the MCA because it is easier to be undetected when being cyber aggressive, allowing one to maintain a positive social image. Therefore, if the perpetrator does not like someone, the internet allows for an easier, and more covert, opportunity to be aggressive against that person. In addition, using aggression to enhance one's Social Image would be easier to perpetrate online 
because the perpetrator would not be able to see the hurt reaction of the victim, and the perpetrator would have an easier time being harsh because of the disconnect and mask of the internet.

In conclusion, the MSA and MCA are more similar than they are different. These scales produced a five-factor structure with 16 similar items in both scales. Thus, there is approximately $75 \%$ of agreement in the reasons reported for using social and cyber-social aggression against a friend, indicating that these two constructs are alike. It is apparent that both social aggression and cyber aggression are used for similar reasons, as both forms of aggression aim to harm another's self-esteem, relationships, and social status (Quigley, 2013; Reynolds \& Repetti, 2010; Varjas, et al., 2010). These findings are also consistent with $\mathrm{Li}$ (2010), who found that youth believe that youth use cyber aggression because they feel insecure, angry, jealous, or bored. In addition, 1 in 5 youth felt that cyber aggression was a 'cool' behaviour (Li, 2010).

Consistently, Reynolds and Repetti (2010) found that amusement, revenge, and acceptance were the most endorsed reasons for using social aggression. These findings are particularly important for bullying interventions. Knowing that youth are using social and cyber-social aggression for the same reasons makes it possible to have more efficient and effective interventions. Promoting positive relationships among youth should be the first step in this intervention, as it seems that the majority of aggressive acts against friends are because youth feel they have been wronged or that they need to prove themselves to fit into a particular group. This will be discussed further in the intervention section. 
Measurement Issues. It is important to note that there were significant measurement issues in the present study. First, as noted above, there were some discrepancies with respect to the frequency of bullying behaviour. Participants appeared reluctant, under certain circumstances, to admit to using social and cyber social aggression with their friends. Thus, although there were 429 participants in the present study, only 189 reported on their reasons for using social aggression with their friends and 115 reported reasons for cyber-social aggression against a friend. This suggests a bias in responding, with students being reluctant to admit to engaging in bullying behaviour.

To better understand the constructs of social and cyber-social aggression it might be beneficial to ask youth why they think 'someone' would use social aggression against a friend rather than only reporting on their own motivations for using this behaviour. Furthermore, only having youth who reported using social aggression against a friend complete the MSA, significantly decreased the sample size in the present study. Having all of the youth report on this measure would help to increase sample size and generalizability of the measure. In addition, this would allow researchers to collect data on those individuals who use social aggression against a friend but do not want to report it, due to a social desirability bias.

Furthermore, there could be other forces that are influencing these behaviours that the present study did not account for, such as, cultural pressures (e.g. feeling the pressure to be nice). Social aggression is often used to aggress against another without being detected. It is possible that individuals are using this behaviour for reasons that are not obvious to them. It may take more probing to get to the core reasons that people are using these behaviours. Future research could use a different technique such as an in-depth 
interview or having the participants keep a diary to better understand their motivations and reasons for using both social and cyber-social aggression.

In addition, as both motivation measures were developed from qualitative research of both forms of aggression, and a previously unvalidated questionnaire (Quigley, 2013), it is possible that there were items that were missed or overly represented in the present study. It is clear that many of the items are awkwardly worded (e.g., 18. I wanted to get my point across to him or her but stay 'looking nice' to the rest of my friends) which is likely to have caused confusion for participants. Furthermore, there were a number of items that did not work in the factor analyses, in part due to wording issues and loading on more than one factor. It is evident that there were a number of issues with regard to measurement structure and working.

Gender differences. Consistent with past research, girls reported using more social aggression than boys. This gender difference was not anticipated as current research indicates that the gender gap is closing, with respect to use of social aggression. Researchers have found that this gap may be closing due to the acceptability of boys using social aggression. However, originally the present study had aimed to have a larger age range of participants. Since the majority of the participants were in late childhood/early adolescence we know that gender differences are more present during those ages (Archer, 2004). These differences become more trivial in later adolescence (Card, et al., 2008). Gender differences were not evident with respect to cyber-social aggression. This is interesting because it may indicate that boys feel more comfortable using socially aggressive behaviours in a cyber environment, because of the anonymity. I 
think it is important that, in future, gender differences are examined with a larger, more generalizable sample.

Overall, there were very few gender differences with regard to the motivations for social and cyber-social aggression. The present study is consistent with the gender similarity hypothesis (Hyde, 2005), which argues that there are more similarities than differences among boys and girls and their use of social aggression. However, there were some gender differences present in the MSA. Girls were found to use social aggression against a friend more often than boys for Acceptance and Jealousy reasons. It is possible that girls are using social aggression more than boys due to the structure of their relationships. Boys tend to be more direct in their friendships, thus would be more likely to deal with issues around jealousy and acceptance rather than be covert. In addition, boys may not take part in socially aggressive behaviours as often as girls, because they will choose to use more direct forms of behaviour, such as physical aggression, when dealing with peer conflict.

There were no gender differences present with regard to the motivations for using cyber-social aggression. This makes sense because girls and boys use cyber-social aggression at a similar rate, whereas on average, girls use more social aggression than boys. The findings with regard to gender differences in the current thesis provide further evidence for the similarities between males and females in their motivations for, and use of, social and cyber-social aggressive behaviours. Perhaps other personal or social characteristics play a role here as well, and future research should aim to explore other factors related to why boys and girls use aggression.

\section{Implications of most endorsed motivations}


Adolescents in the current study endorsed the desire for revenge and the desire for acceptance most highly out of the five possible reasons for using social aggression against a friend. This is consistent with Quigley (2013), and Reynolds and Repetti (2010). Furthermore, youth endorsed the desire for revenge and amusement most highly out of the five possible motivations for using cyber-social aggression against a friend.

It is important to note that the most endorsed reason reported for using both social and cyber-social aggression was revenge. During adolescence, friendships become more important, yet, it is typical that youth will report more conflict with friends at this time (Mcdonald, 2008). Research on social goals, suggests that revenge is very common in adolescent friendships (Frestrom, 2013). Specifically, youth endorsed more revenge goals when faced with major provocation, or feelings of disrespect and rejection from friends (Mcdonald, 2008). It is possible that revenge is endorsed in adolescence due to the need for reciprocity in friendships - referring to the expectations that youth have about equality in their friendship exchanges (Fredstrom, 2013). In addition, youth report using revenge strategies to "get even" with friends (Fredstrom, 2013). This could be particularly true in poor quality friendships, suggesting that those endorsing using revenge against a friend are doing so with peers who are in their friendship group, but might not be close friends. Therefore, it may be important to examine research on friendship quality, and conflict resolution strategies, strategies that could vary as a function of the quality of the relationship.

Another important reason reported for using social aggression against a friend was Acceptance. It is known that friendships are very important in adolescence indicating a need for acceptance among peers. Consistent with past research, the present 
study found acceptance to be a prominent motivator in using social aggression against a friend. Research demonstrates that those who feel rejected by peers are often seen as more aggressive among peers (Zimmer-Gembeck, Nesdale, McGregor, Mastro, Goodwin, \& Downey, 2013). In addition, Reynolds and Repetti (2010) found that if perpetrators felt that their friends did not like the victim, than being socially aggressive toward the victim would help the perpetrator get closer to the group. The problem with this is that youth come to see inclusion in the group as an acceptable reason to use social aggression with their peers (Owens, et al., 2000).

The second most endorsed reason reported for using cyber-social aggression was Amusement. Amusement as a motivator included using cyber-social aggression against a friend to create excitement and alleviate boredom. It is important to acknowledge this motivation and figure out why youth feel this is an acceptable way of alleviating boredom. With regard to social aggression, Owens and colleagues (2000) found that a number of youth used social aggression to entertain themselves because they lacked hobbies and activities. This could also be true for using cyber-social aggression against a friend. It might be necessary to find ways to have youth engage in more extra-curricular activities to keep them from using their free time to engage in aggressive and harmful behaviours. Researchers have found that $64 \%$ of youth reported that cyber aggression happens for fun, and 1 in 5 thought it was a 'cool' behaviour (Li, 2010). Future research should focus on why youth think this harmful behaviour is cool.

\section{Limitations}

It is important to acknowledge the limitations of this study. One limitation is the structure of the motivations measures; it is possible that there are more motivations than 
what the measure encompasses. As previously mentioned, items in the measure were awkwardly worded which may have resulted in confusion for participants. In addition, sample size was an issue. In order to run a reliable factor analyses, it is ideal to have more participants. For these reasons, it is important to interpret results of the present study with caution. The reliability of the results, as well as the validity of the measures themselves, is of some concern.

Another limitation was that the responses from schools were inconsistent. Therefore, it was not possible to run age and grade analyses. Two of the four schools had a much higher response rate. Since these two schools were middle schools we lacked a response from the high school grades to perform age analyses. Lastly, the present study relied on self-report information, and it is often difficult to ensure participants are honest. Although participants were ensured anonymity, some were still likely to behave in a socially desirable way, especially because of the presence of teachers in the classroom.

\section{Future Research}

It is important that future research addresses the following issues: 1) Reporting biases; 2) Measurement issues; and 3) Effective Strategies to decrease these behaviours. Reporting biases are common in research. However, it is important that researchers find a way to get an honest assessment of student bullying behaviour. Past researchers have used interviews to collect more detailed information about bullying behaviour. It is possible that self-reports of bullying behaviour are not the most ideal or accurate way to measure this construct. Self-reports may be more accurate if researchers could prime or prepare students with a short presentation about bullying and how it does not mean that those who use aggression against friends are bad people but that it is common among 
youth and we are trying to improve peer relationships. In addition, it might be helpful to make sure there are no "authority figures" in the classroom to make students feel more comfortable.

It is evident that there were a number of measurement issues with this study. The motivation measures could be more effective if they were modified to contain more 'to the point' wording (e.g. I was jealous of his/her romantic relationship). Furthermore, it would be beneficial to have students complete all parts of the survey to increase sample size and thus the generalizability of the study. Rather than only have those who reported using aggression against a friend report on the motivations, students could speculate by using hypothetical reports (e.g. Some teens might post mean or embarrassing photos of a friend online; Why would they do this? For reasons such as: Jealousy, Revenge, Amusement, Social Image, or Anonymity (and give examples of the behaviour)).

The frequency and motivations for using social and cyber-social aggression against a friend should be central in developing interventions for youth. It is important to make youth aware of the harmful consequences of victimizing a friend. Furthermore, educators should use the knowledge about motivations as a basis for improving youth's friendships. For example, having assertiveness training in schools could help youth be more upfront and honest with friends when they are experiencing conflict rather than using social or cyber-social aggression to get revenge on these individuals.

It is clear that addressing the issue of social and cyber-social aggression should be a collective effort among schools, families, policy makers, and youth. Schools could help by developing rules to stop the use of social and cyber-social aggression in school. In addition, educators could complete anti-bullying training to help them notice the 
aggressive acts used by students, and provide them with the tools to address these issues.

Families could contribute by attending information sessions on aggression and bullying, and by trying to create a safe environment where their children feel safe reporting aggression and talking openly about their own and other students' behaviours.

Another intervention technique would be to have policies in place to protect those being victimized, whether it is in school, the community, or both. It is important that someone is monitoring those behaviours, for example, ensuring there are help lines, websites, and support groups for those being victimized and those who are perpetrating the behaviour. Lastly, it is the responsibility of youth to learn that they have a responsibility to their peers to be kind and respectful. Promoting healthy relationships among youth could be the first step in improving relationships. Also, youth need to be aware of the consequences and harm that can arise from hurting another person. Students need to understand the importance of reporting these incidences and seeking help for themselves or others who are being victimized, and for those who are victimizing others.

\section{Conclusion}

The purpose of the present study was to examine the motivations associated with using social and cyber-social aggression. Such research is valuable, given the potential harmful consequences of being victimized by one's peers in this way. Although some researchers think that social aggression is normative due to the high frequency of these behaviours (Vaillancourt, et al., 2010), social and cyber-social aggression always result in harm to the victim. The growing prevalence of cyber-social aggression against a friend has allowed youth to have another way to harm each other, which is arguably a more harmful tool due to the high degree of anonymity online. 
Results highlighted the fact that the reasons for using social aggression and cyberaggression are quite similar, with youth endorsing Revenge as a common goal in both cases. Novel contributions of this research include the assessment of the frequency of aggressive behaviour towards friends in a large sample of boys and girls; the development of a new measure of motivation for using cyber social aggression against one's friends; and the inclusion of Anonymity as a reason reported for using both social and cyber-social aggression. A stronger understanding as to the reasons for why adolescents engage in these behaviours with their friends is essential for the development of successful intervention programs, both at school and within the larger community. 


\section{References}

Archer, J. \& Coyne, S. M. (2005). An integrated review of indirect, relational, and social aggression. Personality and Social Psychology Review, 9, 212-230. doi: $10.1207 / \mathrm{s} 15327957 \mathrm{pspr} 0903 \_2$

Archer, J. (2004). Sex differences in aggression in real-world settings: A meta-analytic review. Review of General Psychology, 8, 291-322. doi: 10.1037/10892680.8.4.291

Banergee, S. (2013, October 3). Rehtaeh Parsons' father says she wanted to go to the media before her suicide. The Canadian Press. Retrieved from: http://globalnews.ca/news/881297/rehtaeh-parsons-father-says-she-wanted-to-goto-the-media-before-her-suicide/

Baumeister, R. F. \& Leary, M. R. (1995). The need to belong: Desire for interpersonal attachments as a fundamental human motivation. Psychological Bulletin, 117, 497-529.

Bentler, P.M. (1990), "Comparative Fit Indexes in Structural Models," Psychological Bulletin, 107 (2), 238-46.

Berger, K. (2007). Update on school bullying at school: Science forgotten? Development Review, 27, 90-126.

Burke, A. (2011, October 18). Gay Ottawa teen who killed himself was bullied. Canadian Broadcasting Corporation. Retrieved from: http://www.cbc.ca/news/canada/ottawa/gay-ottawa-teen-who-killed-himself-wasbullied-1.1009474 
Cairns, R. B., Cairns, B. D., Neckerman, H. J., Ferguson, L. L., \& Gariépy, J.-L. (1989). Growth and aggression: I. Childhood to early adolescence. Developmental Psychology, 25, 320-330. doi: 10.1037/0012-1649.25.2.320

Canadian Press. (2012, October 12). Weeks after posting haunting YouTube video on her years of torment at classmates' hands, 15-year-old B.C. girl commits suicide. Retrieved from : http://news.nationalpost.com/2012/10/12/amanda-todd-suicide$\underline{2012 /}$

Card, N. A., Stucky, B. D., Sawalani, G. M., \& Little, T. D. (2008). Direct and indirect aggression during childhood and adolescence: A meta-analytic review of gender differences, intercorrelations, and relations to maladjustment. Child Development, 79, 1185-1229. doi: 10.1111/j.1467-8624.2008.01184.x

Cassidy, W., Jackson, M., \& Brown, K. N. (2009). Sticks and stones can break my bones, but how can pixels hurt me? School Psychology International, 30 (4), 383-402. Doi: $10.1177 / 0143034309106948$

Coyne, S. M., Archer, J., \& Eslea, M. (2006). "We're not friends anymore! Unless...”: The frequency and harmfulness of indirect, relational, and social aggression. Aggressive Behavior, 32, 294-307.

Crick, N. R., \& Grotpeter, J. K. (1995). Relational aggression, gender, and social psychological adjustment. Child Development, 66, 710-722. doi: $10.2307 / 1131945$

Crick, N. R., Bigbee, M. A., \& Howes, C. (1996). Gender differences in children's normative beliefs about aggression: How do I hurt thee? Let me count the ways. Child Development, 67, 1003-1014. 
Crick, N. R., Casas, J. F. and Ku, H-C. (1999). Relational and physical forms of peer victimization in preschool. Developmental Psychology, 35, 2. pp. 376-385.

Crick, N. R., Nelson, D. A., Morales, J. R., Cullerton-Sen, C., Casas, J. F., \& Hickman, S. (2001). Relational victimization in childhood and adolescence: I hurt you through the grapevine. In J. Juronen \& S. Graham (Eds), School-based peer harassment: The plight of the vulnerable and victimized (p. 196-214). New York: Guilford Press.

Daniels, T., Quigley, D., Menard, L., \& Spence, L. (2010). “My best friend always did and still does betray me constantly": Examining relational and physical victimization within a dyadic friendship context. Canadian Journal of School Psychology, 25, 70-83. doi: 10.1177/0829573509357531

Delveaux, K. D. \& Daniels, T. (2000). Children's social cognitions: Physically and relationally aggressive strategies and children's social goals in peer conflict situations. Merrill-Palmer Quarterly, 46, 672-692. Available at: http://digitalcommons.wayne.edu/mpq/vol46/iss4/9

Field, A (3rd ed.) (2009) Discovering Statistics using SPSS. London: Sage.

Fredstrom, B. K. (2013). The link between relationship orientations and friendship quality: The mediating roles of social goals and resolution strategies. University of Maryland, College Park). ProQuest Dissertations and Theses, 292. Retrieved from http://search.proquest.com/docview/1432193546?accountid=9894. (1432193546)

Galen, B. R. \& Underwood, M. K. (1997). A developmental investigation of social aggression among children. Developmental Psychology, 33, 589-600. doi: $10.1037 / 0012-1649.33 .4 .589$ 
Gentry, J. H. \& Campbell, M. (2002). Developing Adolescents: A reference for professionals. Washington, DC: American Psychological Association.

Gradinger, P., Strohmeier, D., \& Spiel, C. (2010). Definition and measurement of cyberbullying. Cyberpsychology: Journal of psychosocial research on cyberspace, $4(2)$, article 1 .

Hinduja, S. \& Patchin, J. W. (2008). Cyberbullying: An exploratory analysis of factors related to offending and victimization. Deviant Behavior, 29, 129-156. Doi: $10.1080 / 01639620701457816$

Hinduja, S. \& Patchin, J. W. (2009). Bullying beyond the schoolyard: Preventing and responding to cyberbullying. Thousand Oaks, CA: Sage Publications.

Lagerspetz, K. M., Björkqvist, K., \& Peltonen, T. (1988). Is indirect aggression typical of females? Gender differences in aggressiveness in 11- to 12-year-old children. Aggressive Behavior, 14, 403-414. doi: 10.1002/1098-2337(1988)14:6<403::AID$\mathrm{AB} 2480140602>3.0 . \mathrm{CO} ; 2-\mathrm{D}$

Law, D. M., Shapka, J. D., Domene, J. F., \& Gagne, M. H. (2012). Are cyberbullies really bullies? An investigation of reactive and proactive online aggression. Computers in Human Behavior, 28 (2), 664-672. Doi: 10.1016/j.chb.2011.11.013

Li, Q. (2006). Cyberbullying in schools: A research of gender differences. School Psychology International, 27 (2), 157-170. Doi: 10.1177/0143034306064547

Li, Q. (2007). New bottle but old wine: A research of cyberbullying in schools. Computers in Human Behavior, 23, 1777-1791. Doi: 10.1016/j.chb.2005.10.005 
Li, Q. (2008). A cross-cultural comparison of adolescents' experiences related to cyberbullying. Educational Research, 50 (3), 223-234. Doi:

$10.1080 / 00131880802309333$

Li, Q. (2010). Cyberbullying in high schools: A study of students' behaviors and beliefs about this new phenomenon. Journal of Aggression, Maltreatment \& Trauma, 19, 372-392. Doi: 10.1080/10926771003788979

Mcdonald, K. L. (2008). Interpretations and beliefs associated with children's revenge goals in conflict situations. Dissertation Abstracts International: Section B: The Sciences and Engineering, 1362. Retrieved from http://search.proquest.com/docview/621742000?accountid=9894. (621742000; 2008-99160-360)

Media Awareness Network, (2005). "Young Canadians in a Wired World - Phase II: Key Findings." Retrieved from: http://www.rcmp-grc.gc.ca/nsci-ecsn/rad/rad-eng.htm Olweus, D. (1994). Annotation: Bullying at school: Basic facts and effects of a school based intervention program. Journal of Child Psychology and Psychiatry, 35, 11711190.

Orr, J. M., Sackett, P. R., \& Dubois, C. L. Z. (1991). Outlier detection and treatment in I/O psychology: A survey of researcher beliefs and an empirical illustration. Personnel Psychology, 44, 473-486. doi: 10.1111/j.1744-6570.1991.tb02401.x

Ostrov, J. M. \& Keating, C. F. (2004). Gender differences in preschool aggression during free play and structured interactions: An observational study. Social Development, 13 (2), 255-277. 
Owens, L., Slee, P., \& Shute, R. (2000). 'It hurts a hell of a lot...' The effects of indirect aggression on teenage girls. School Psychology International, 21, 359-376. doi: DOI: $10.1177 / 0143034300214002$

Owens, L., Shute, R., \& Slee, P. (2000a). 'I'm in and you're out...': Explanations for teenage girls' indirect aggression. Psychology, Evolution \& Gender 2, 19-46. doi: $10.1080 / 14616660050082906$

Patchin, J. W. \& Hinduja, S. (2006). Bullies move beyond the schoolyard: A preliminary look at cyberbullying. Youth Violence and Juvenile Justice, 4(2), 148-169. doi:10.1177/1541204006286288

Pronk, R. E. \& Zimmer-Gembeck, M. J. (2010). It's “mean,” but what does it mean to adolescents? Relational aggression described by victims, aggressors, and their peers. Journal of Adolescent Research, 25, 175-204. doi:

$10.1177 / 0743558409350504$

Quigley, D. (2013) Dissertation. "I did it because she hurt me”: Investigating motivations for social aggression in youth.

Reynolds, B. M. \& Repetti, R. L. (2010). Teenage girls' perceptions of the functions of relationally aggressive behaviors. Psychology in the Schools, 47, 282-296.

Salmivalli, C., Kaukiainen, A., \& Lagerspetz, K. (2000). Aggression and sociometric status among peers: Do gender and type of aggression matter? Scandinavian Journal of Psychology, 41 (1), 17-24.

Sevcikova, A., Smahel, D., \& Otavova, M. (2012). The perception of cyberbullying in adolescent victims. Emotional and Behavioural Difficulties, 17 (3-4), 319-328. Doi: 10.1080/13632752.2012.704309 
Slonje, R. \& Smith, P. K. (2008). Cyberbullying: Another main type of bullying? Scandinavian Journal of Psychology, 49, 147-154. Doi: 10.1111/j.14679450.2007.00611.x

Smith, P. K., Mahdavi, J., Carvalho, M., Fisher, S., Russell, S., \& Tippett, N. (2008). Cyberbullying: Its nature and impact in secondary school pupils. Journal of Child Psychology and psychiatry, 49 (4), 376-385. Doi: 10.1111/j.14697610.2007.01846.x

Tabachnick, B. G. \& Fidell, L. S. (2007). Using Multivariate Statistics (5th edition). Boston: Pearson Education.

Tokunaga, R. S. (2010). Following you home from school: A critical review and synthesis of research on cyberbullying victimization. Computers in Human Behavior, 26, 277-287. Doi: 10.1016/j.chb.2009.11.014

Underwood, M. K. (2003). Social aggression among girls. New York: Guilford Press. Vaillancourt, T., McDougall, P., Hymel, S., \& Sunderani, S. (2010). Respect or fear? The relationship between power and bullying behaviour. In S. R. Jimerson (Ed.), Handbook of Bullying in Schools: An International Perspective. New York: Taylor and Francis.

Varjas, K., Talley, J., Meyers, J., Parris, L., \& Cutts, H. (2010). High school students' perception of motivations for cyberbullying: An exploratory study. West J Emerg Med., 11 (3), 269-273.

Wang, J., Iannotti, R. J., \& Nasel, T. R. (2009). School bullying among adolescents in the United States: Physical, verbal, relational, and cyber. Journal of Adolescent Health, $45(4), 368-375$. 
Willard, N. (2004a). An educator's guide to cyberbullying and cyberthreats. Retrieved from http://cyberbully.org/docs/cbcteducator.pdf

Williams, K. R. \& Guerra, N. G. (2007). Prevalence and predictors of Internet bullying. Journal of Adolescent Health, 41, S14-S21.

Wolak, J., Mitchell, K., \& Finkelhor, D. (2006). Online victimization: 5 years later (NCMEC 07-06-025). Alexandria, VA: National Center for Missing \& Exploited Children.

Ybarra, M. L., Boyd, D., Korchmaros, J. D. \& Oppenheim, J. (2012). Defining and measuring cyberbullying within the larger context of bullying victimization. Journal of Adolescent Health 51, 53-58. Doi: 10.1016/j.jadohealth.2011.12.031

Ybarra, M. L. \& Mitchell, K. J. (2007). Prevalence and frequency of Internet harassment instigation: Implications for adolescent health. Journal of Adolescent Health, 41, 189-195. Doi: 10.1016/j.jadohealth.2007.03.005

Ybarra, M. L. \& Mitchell, K. J. (2004). Online aggressor/targets, aggressors, and targets: A comparison of associated youth characteristics. Journal of Child Psychology and Psychiatry, 45 (7), 1308-1316. Doi: 10.1111/j.1469-7610.2004.00328.x

Zimmer-Gembeck, M., Nesdale, D., McGregor, L., Mastro, S., Goodwin, B., \& Downey, G. (2013). Comparing reports of peer rejection: Associations with rejection sensitivity, victimization, aggression, and friendship. Journal of Adolescence, 36(6), 1237-1246. doi:http://dx.doi.org/10.1016/j.adolescence.2013.10.002 
Table 1

Frequency of Grade and Gender of Participants

\begin{tabular}{lccc}
\hline Grade & Total (\%) & Females $(\%)$ & Males (\%) \\
\hline 6 & $145(36.4)$ & $85(37.4)$ & $60(35.1)$ \\
7 & $61(15.3)$ & $39(17.2)$ & $22(12.9)$ \\
8 & $122(30.7)$ & $66(29.1)$ & $56(32.7)$ \\
9 & $16(4.0)$ & $7(3.1)$ & $9(5.3)$ \\
10 & $18(4.5)$ & $15(6.6)$ & $3(1.8)$ \\
11 & $21(5.3)$ & $8(3.5)$ & $13(7.6)$ \\
12 & $\underline{14(3.5)}$ & $\underline{6(2.6)}$ & $\underline{8(4.7)}$ \\
Total & $398(100 \%)$ & $227(57 \%)$ & $171(43 \%)$ \\
\hline
\end{tabular}


Table 2

Means, Standard Deviations and Gender Differences for frequency of Social Aggression against a friend

\begin{tabular}{lccc} 
& Overall & Females & Males \\
\cline { 2 - 4 } Item & $M(S D)$ & $M(S D)$ & $M(S D)$
\end{tabular}

1. Deliberately ignored a friend in order to

$.38(.65) \quad .35(.62) \quad .43(.68)$

exclude, alienate, or embarrass him or her

2. Spread rumours or said something

$.70(1.07)$

$.83(1.20)$

$.54(.87)$

negative about a friend who wasn't there

at the time (i.e. gossiped)

3. Kept a friend from being accepted by

$.25(.64)$

$.24(.58)$

$.27(.71)$

your group of friends

4. Tried to steal the guy/girl another friend

$.18(.59)$

$.23(.69)$

$.11(.43)$

liked

5. Gave a friend the "silent treatment"

$.84(1.07)$

.95 (1.07)

$.70(1.06)$

6. Tried to get your friends not to like a

$.35(.84)$

$.39(.89)$

$.29(.78)$

particular friend

7. Talked behind a friend's back

$1.09(1.30) \quad 1.24(1.38) \quad .90(1.16)$

8. Turned away or kept talking when a

$.62(.96)$

$.69(.1 .02)$

$.53(.88)$

friend came over to say something

9. Gave a friend dirty looks

$.84(1.24)$

$.87(1.26)$

10. Rolled eyes at a friend

$1.21(1.47)$

$1.32(1.52)$

$1.07(1.41)$

11. Passed a friend a note with something

$.11(.54)$

$.09(.43)$

$.13(.65)$

mean written on it or written the note and gotten someone else to pass it (e.g. a note that says "no one likes you")

12. Stopped talking when a friend came

$.45(.91)$

$.52(.93)$

$.36(.87)$

over to you and a friend so he or she couldn't join the conversation

13. Made a mean face when asked to be

$.51(.92)$

$.54(.89)$

$.48(.96)$ partners with a guy/girl for a school 
project

14. Glared or stared at a guy/girl meanly $\quad .58(1.02) \quad .69(1.13) \quad .45(.86)$

15. Didn't invite a friend to a party to be $\quad .16(.61) \quad .18(.59) \quad .14(.64)$

hurtful even though he/she wanted to

come 
Table 3

Means, Standard Deviations and Gender Differences for frequency of Cyber-social Aggression against a Friend

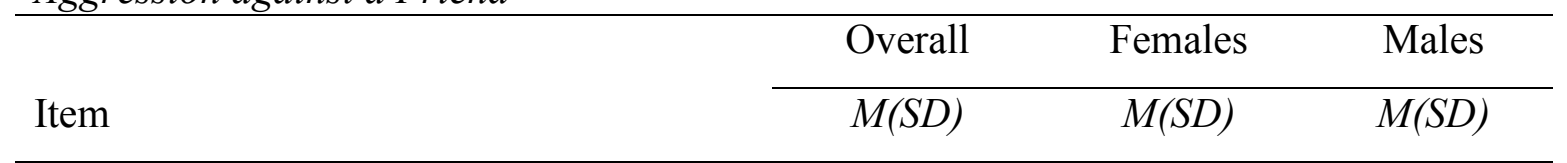

1. Deliberately ignore a friend's emails, $.69(1.05)$

$.69(1.03)$

$.69(1.10)$

texts, facebook posts etc. in order to

exclude, alienate, or embarrass him or her

online

2. Spread rumours or wrote something

negative about a friend online (i.e. gossiped)

3. Kept a friend from being accepted by $.36(.84)$

your group of friends by blocking them or refusing to respond to emails, text messages, facebook posts, etc.

4. Tried to steal the guy/girl a friend liked $.37(.86)$

by flirting with him or her through facebook, text messages, emails, etc.

5. Tried to get your friends not to like a $.22(.64)$ $.20(.60)$ $.25(.69)$ particular friend by making mean or untrue posts about him or her online

6. Posted a mean or embarrassing pictures $.48(.1 .04)$ of a friend online

7. Made a webpage or added to a webpag $.12(.58)$ $.14(.67)$ or group message putting down another friend (e.g. "She's so ugly")

8 Not invited a friend to an event or group $.29(.76)$ $.23(.65)$ $.40(.90)$ online knowing that he or she would like to join

9. Given a friend the silent treatment $1.14(1.28)$ $1.25(1.29)$ $.95(1.25)$ 
online by ignoring his or her messages

10. Sent mean, hostile, or intimidating

$.37(.81)$

$.27(.85)$

messages to a friend online

11. Told a friend you did not like him or

$.44(1.02)$

$.29(.75)$

her online

12. Pretended to be a friend online to

$.19(.52)$

embarrass him or her

13. Tricked a friend into sharing personal

$.15(.57)$

$.12(.58)$

$.19(.55)$

information that you could use against him

or her through email, chatrooms, etc.

14. Shared a friend's personal information

$.11(.50)$

$.13(.60)$

$.07(.26)$

to embarrass him or her online

15. Told a friend's secret online to

$.14(.53)$

$.16(.61)$

$.11(.41)$

publically embarrass him or her 
Table 4

Means and Standard Deviations for the Motivations for Social Aggression Scale

\begin{tabular}{lllll}
\hline Items & $\mathrm{N}$ & $M$ & $S D$
\end{tabular}

1. I thought it would help me get closer to one or more other

$186 \quad 1.67 \quad 1.12$
friends

2. I thought one or more of my friends didn't like him/her

$183 \quad 2.11 \quad 1.34$

3. I thought it would get me closer to a guy/girl I liked

$181 \quad 1.57 \quad 1.15$

4. I just wanted to be accepted by the group

$184 \quad 1.67 \quad 1.13$

5. I thought it would make me more popular

179

6. I was trying to get back at him/her for something he/she did

$186 \quad 3.02$

1.00

that made me mad

7. I was angry about something and wanted to put him/her in

183

his/her place

8. I wanted to belong to the 'right' group of friends

$183 \quad 1.72 \quad 1.21$

9. It seemed like a fun thing to do at the time

$183 \quad 1.79 \quad 1.28$

10. I was bored

$183 \quad 1.65 \quad 1.19$

11. I didn't have anything better to do

$182 \quad 1.55 \quad 1.05$

12. I thought it would be exciting

$\begin{array}{lll}183 & 1.52 & 1.08\end{array}$

13. I thought he/she was going to do something bad to me so I

$183 \quad 1.55$

1.04 wanted to do something to him/her first

14. I was jealous about another relationship that was developing

1.29 between him/her and one of my other friends

15. I was jealous of a relationship that was developing between

$181 \quad 1.59$ him/her and a guy/girl

16. I felt insecure about my friendships

$182 \quad 1.68 \quad 1.11$

17. I wanted to avoid getting in trouble with adults

$179 \quad 1.55 \quad 1.16$

18. I wanted to get my point across to him/her but stay 'looking

18

1.84

1.27 nice' to the rest of my friends

19. I figured it was a socially acceptable way of getting out my

$181 \quad 1.65$ anger 
20. I wanted people to still think I was nice

$\begin{array}{lll}180 & 1.83 \quad 1.25\end{array}$

21. I thought he/she wasn't cool

$180 \quad 1.63 \quad 1.19$

22. I thought he/she was too emotional

$\begin{array}{lll}178 & 1.76 & 1.28\end{array}$

23. I was envious of something he/she had

$178 \quad 1.41 \quad 0.92$

24. I was jealous of him/her

$180 \quad 1.52 \quad 1.06$

25. I thought I would not get in trouble

$179 \quad 1.58 \quad 1.14$

26. I thought it was unlikely that I would get caught

$180 \quad 1.75 \quad 1.28$

27. I thought it was unlikely that anyone would know who did it $\begin{array}{llll}179 & 1.45 & 1.03\end{array}$ 


\section{Table 5}

Factor Loadings for Exploratory Factor Analysis on the Motivations for Social Aggression Scale

\begin{tabular}{|c|c|c|c|c|c|}
\hline Item & Acceptance & Revenge & Amusement & Jealousy & Anonymity \\
\hline $\begin{array}{l}\text { 1. I thought it would help me get closer to } \\
\text { one or more other friends }\end{array}$ & $.647^{*}$ & -.124 & .009 & $.217^{*}$ & -.097 \\
\hline $\begin{array}{l}\text { 2. I thought one or more of my friends } \\
\text { didn't like him/her }\end{array}$ & $.373^{*}$ & .030 & .032 & .103 & .101 \\
\hline $\begin{array}{l}\text { 3. I thought it would get me closer to a } \\
\text { guy/girl I liked }\end{array}$ & $.478^{*}$ & -.044 & $.179 *$ & $.271 *$ & -.114 \\
\hline $\begin{array}{l}\text { 4. I just wanted to be accepted by the } \\
\text { group }\end{array}$ & $.774 *$ & -.085 & .014 & .026 & -.015 \\
\hline $\begin{array}{l}\text { 5. I thought it would make me more } \\
\text { popular }\end{array}$ & $.425 *$ & $-.200 *$ & $.190 *$ & $.289 *$ & .083 \\
\hline $\begin{array}{l}\text { 8. I wanted to belong to the 'right' group } \\
\text { of friends }\end{array}$ & $.838 *$ & .003 & .016 & -.111 & .047 \\
\hline 16. I felt insecure about my friendships & $.480 *$ & .047 & -.093 & $.295 *$ & .009 \\
\hline $\begin{array}{l}\text { 17. I wanted to avoid getting in trouble } \\
\text { with adults }\end{array}$ & $.620 *$ & $.156 *$ & .013 & -.051 & .031 \\
\hline $\begin{array}{l}\text { 20. I wanted people to still think I was } \\
\text { nice }\end{array}$ & $.678^{*}$ & .081 & -.050 & -.030 & .087 \\
\hline $\begin{array}{l}\text { 6. I was trying to get back at him/her for } \\
\text { something he/she did that made me mad }\end{array}$ & -.099 & $.749 *$ & -.004 & .142 & .043 \\
\hline $\begin{array}{l}\text { 7. I was angry about something and } \\
\text { wanted to put him/her in his/her place }\end{array}$ & .041 & $.842 *$ & .068 & -.029 & -.032 \\
\hline $\begin{array}{l}\text { 9. It seemed like a fun thing to do at the } \\
\text { time }\end{array}$ & -.048 & .036 & $.899 *$ & .021 & -.018 \\
\hline 10. I was bored & .007 & -.031 & $.740 *$ & .036 & -.029 \\
\hline 12. Thought it would be exciting & .041 & .011 & $.757 *$ & -.063 & .101 \\
\hline 14. I was jealous about another & -.031 & .008 & -.054 & $.828 *$ & .030 \\
\hline $\begin{array}{l}\text { Relationship that was developing } \\
\text { between him/her and one of my other } \\
\text { friends }\end{array}$ & & & & & \\
\hline $\begin{array}{l}\text { 15. I was jealous of a relationship that } \\
\text { was developing between him/her and } \\
\text { guy/girl }\end{array}$ & -.004 & .069 & -.004 & $.729 *$ & .109 \\
\hline 23. I was envious of something he/she & .061 & -.025 & .005 & $.646 *$ & .145 \\
\hline
\end{tabular}


had

24. I was jealous of him/her

$\begin{array}{lllll}.088 & .060 & .057 & . \mathbf{7 4 8 *} & -.077\end{array}$

25. I thought I would not get in trouble

$\begin{array}{lllll}.055 & -.073 & .043 & -.043 \quad \mathbf{8 4 6 *}\end{array}$

26. I thought it was unlikely I would get

$-.070$

$.009-.001$

$.221 *$

$.729 *$

caught

27. I thought it was unlikely anyone

.221

.027

$-.015$

.100

$.575^{*}$

would know who did it

13. I thought he/she was going to do

$.260 *$

$.288 *$

$.203 *$

.017

.012

something bad to me so I wanted to do

something to him/her first

18. I wanted to get point across to

$.412 *$

$-.105$

.014

$-.030$

$\mathrm{him} /$ her but stay 'looking nice' to the rest

of my friends

19. I figured it was a socially acceptable

.231

$.294 *$

.066

.041

$.253 *$

way of getting out my anger

21. I thought he/she wasn't cool

$.296 *$

.126

$.279 *$

$-.003$

.122

22. I thought he/she was too emotional

$.317^{*}$

.148

$.170 *$

.018

.160

$* p<.05$

Note: Items that are highlighted were removed from subsequent analyses. 
Table 6

Fit Indices for the Motivations for Social Aggression Scale Exploratory Factor Analysis: Including all 26 items

\begin{tabular}{ccccccccc} 
Model & $\chi^{2}$ & $d f$ & $p$ & $C F I$ & $T L I$ & SRMR & RMSEAR & AIC \\
& & & & & & & & \\
\hline 3-factor & 841.592 & 250 & 0.000 & 0.736 & 0.657 & 0.074 & 0.112 & $13,498.182$ \\
& & & & & & & & \\
4-factor & 647.652 & 227 & 0.000 & 0.812 & 0.731 & 0.056 & 0.099 & $13,350.243$ \\
5-factor & $\mathbf{5 0 3 . 4 7 7}$ & $\mathbf{2 0 5}$ & $\mathbf{0 . 0 0 0}$ & $\mathbf{0 . 8 6 7}$ & $\mathbf{0 . 7 8 9}$ & $\mathbf{0 . 0 4 3}$ & $\mathbf{0 . 0 8 8}$ & $\mathbf{1 3 , 2 5 0 . 0 6 7}$ \\
& & & & & & & & \\
6-factor & 389.588 & 184 & 0.000 & 0.908 & 0.838 & 0.034 & 0.077 & $13,178.178$ \\
& & & & & & & & \\
\hline
\end{tabular}


Table 7

Factory Loadings for Confirmatory Factor Analysis for Motivations for Social Aggression

Item Acceptance Revenge Amusement Jealous Anonymity

1. I thought it would help me get closer to $.721 *$ one or more other friends

2. I thought one or more of my friends didn't like him/her

3. I thought it would get me closer to a

$.668 *$ guy/girl I liked

4. I just wanted to be accepted by the group

5. I thought it would make me more

$.699 *$ popular

8. I wanted to belong to the 'right' group of friends

16. I felt insecure about my friendships

$.597 *$

17. I wanted to avoid getting in trouble

$.600 *$ with adults

20. I wanted people to still think I was nice

6. I was trying to get back at him/her for $.968 *$ something he/she did that made me mad 7. I was angry about something and wanted to put him/her in his/her place 9. It seemed like a fun thing to do at the time

10. I was bored

12. Thought it would be exciting

14. I was jealous about another

Relationship that was developing between him/her and one of my other friends

15. I was jealous of a relationship that was developing between him/her and guy/girl 23. I was envious of something he/she had $.745 *$ 24. I was jealous of him/her

25. I thought I would not get in trouble

26. I thought it was unlikely I would get 
caught

27. I thought it was unlikely anyone would

know who did it

${ }^{*} p<.05$ 
Table 8

\begin{tabular}{l} 
Means and Standard Deviations for the Motivations for Cyber-social Aggression Scale \\
\hline Items
\end{tabular}

6. I was trying to get back at him/her for something he/she did $\quad \begin{array}{llll}113 & 2.81 & 1.71\end{array}$ that made me mad

7. I was angry about something and wanted to put him/her in $\quad \begin{array}{lll}113 & 2.55 & 1.61\end{array}$ his/her place

18. I wanted to get my point across to him/her but stay 'looking $\quad \begin{array}{llll}111 & 1.93 & 1.34\end{array}$ nice' to the rest of my friends

19. I figured it was a socially acceptable way of getting out my $\quad \begin{array}{llll}111 & 1.89 & 1.36\end{array}$ anger

9. It seemed like a fun thing to do at the time

$113 \quad 1.89 \quad 1.37$

2. I thought one or more of my friends didn't like him/her $\quad \begin{array}{llll}114 & 1.85 & 1.23\end{array}$

12. I thought it would be exciting $\quad \begin{array}{lll}113 & 1.79 & 1.22\end{array}$

26. I thought it was unlikely that I would get caught $\quad \begin{array}{lll}110 & 1.78 & 1.31\end{array}$

13. I thought he/she was going to do something bad to me so I $\quad \begin{array}{llll}112 & 1.77 & 1.21\end{array}$ wanted to do something to him/her first

22. I thought he/she was too emotional $\quad \begin{array}{llll}111 & 1.77 & 1.29\end{array}$

10. I was bored $\quad \begin{array}{lll}112 & 1.73 & 1.19\end{array}$

20. I wanted people to still think I was nice $\quad \begin{array}{lll}111 & 1.71 & 1.18\end{array}$

21. I thought he/she wasn't cool $\quad \begin{array}{llll}111 & 1.68 & 1.14\end{array}$

$\begin{array}{llll}\text { 11. I didn't have anything better to do } & 113 & 1.68 & 1.18\end{array}$

16. I felt insecure about my friendships $\quad \begin{array}{lll}111 & 1.65 & 1.09\end{array}$

1. I thought it would help me get closer to one or more other $\quad \begin{array}{lll}114 & 1.65 & 1.14\end{array}$ friends

25. I thought I would not get in trouble $\quad \begin{array}{lll}110 & 1.65 & 1.18\end{array}$

14. I was jealous about another relationship that was developing $\quad \begin{array}{llll}111 & 1.60 & 1.17\end{array}$ between him/her and one of my other friends

3. I thought it would get me closer to a guy/girl I liked $\quad \begin{array}{llll}113 & 1.59 & 1.17\end{array}$

$\begin{array}{llll}\text { 4. I just wanted to be accepted by the group } & 113 & 1.57 & 1.03\end{array}$

24. I was jealous of him/her $\quad \begin{array}{lll}111 & 1.57 & 1.09\end{array}$ 
8. I wanted to belong to the 'right' group of friends

$113 \quad 1.54 \quad 1.01$

15. I was jealous of a relationship that was developing between

$\begin{array}{lll}111 & 1.54 & 1.15\end{array}$ him/her and a guy/girl

17. I wanted to avoid getting in trouble with adults

$111 \quad 1.53 \quad 1.05$

5. I thought it would make me more popular

$113 \quad 1.50 \quad 0.97$

23. I was envious of something he/she had

$110 \quad 1.50 \quad 1.09$

27. I thought it was unlikely that anyone would know who did it $\quad \begin{array}{llll}110 & 1.47 & 1.01\end{array}$ 
Table 9

Factor loadings for Exploratory Factor Analysis for Motivations for Cyber-social Aggression Scale

Jealousy Revenge Amusement Social Anonymity

Image

1. I thought it would help me get closer to

$.528 *$

.119

$-.082$

.082

$.254 *$ one or more other friends

3. I thought it would get me closer to a

$.549 *$

$-.124$

.005

$.247 *$

.095 guy/girl I liked

4. I just wanted to be accepted by the group

5. I thought it would make me more popular

$-.028$

.069

.076

.162

$.637 * \quad-.042$

.110

.009

.181

14. I was jealous about another relationship

$.800 *$

.000

.033

.117

that was developing between him/her and

one of my other friends

15. I was jealous of a relationship that was

$.897 *$

.119

$-.058$

$-.108$

$-.118$

developing between him/her and a guy/girl

16. I felt insecure about my friendships

$.458 * \quad .120$

$-.130$

.217

$.199 *$

23. I was envious of something he/she had

$.882 * \quad .010$

.051

$-.013$

$-.029$

24. I was jealous of him/her

.798* $\quad-.071$

.028

$-.072$

.103

6. I was trying to get back at him/her for

.068

$.850 *$

.022

$-.028$

.048

something he/she did that made me mad

7. I was angry about something and wanted

$-.01$

$.673 *$

.052

.208

.021

to put him/her in his/her place

9. It seemed like a fun thing to do at the time

.006

10. I was bored

$-.041$

.065

$.837 *$

$-.128$

.045

11. I didn't have anything better to do

.028

.015

$.860 *$

.034

.138

8. I wanted to belong to the 'right' group of

.146

$-.007$

$.820 \%$

.176

$-.039$ friends

18. I wanted to get my point across to

$-.011$

$-.093$

$.685 *$

.079

him/her but stay 'looking nice' to the rest of my friends

20. I wanted people to still think I was nice

21. I thought he/she wasn't cool

.171

$-.041$

$-.104$

$.420 *$

.200

.020

$-.035$

.113

$.604 *$

.215

22. I thought he/she was too emotional

$-.023$

.067

.115

$.717 *$

$-.125$

25 . I thought I would not get in trouble

.05

$-.023$

.100

.022

$.762 *$

26. I thought it was unlikely that I would get

.026

.155

$-.002$

$-.034$

$.911 *$ 
27. I thought it was unlikely that anyone $-.053$ .185

$-.020$

$.257 *$

$.595 *$

would know who did it

2. I thought one or more of my friends didn't

$.381 *$

.087

$-.099$

$.344 *$

$-.059$

like him/her

13. I thought he/she was going to do

.278

$.241 *$

$.268 *$

$.323 *$

something bad to me so I wanted to do

something to him/her first

17. I wanted to avoid getting in trouble with

.218

$-.090$

.099

$.395 *$

$.262 *$ adults

19. I figured it was a socially acceptable way

$-.001$

$.294 *$

.066

.271

.184

of getting out my anger

$* p<.05$

Note: Items that are highlighted were removed from subsequent analyses. 
Table 10

Fit Indices for Motivations for Cyber-social Aggression Scale Exploratory Factor Analysis: Including all 26 items

\begin{tabular}{lcccccccc}
\hline Model & $\chi^{2}$ & $d f$ & $p$ & $C F I$ & $T L I$ & SRMR & RMSEA & AIC \\
\hline 3- & 637.506 & 250 & 0.000 & 0.784 & 0.719 & 0.063 & 0.116 & 8016.832 \\
factor & & & & & & & & \\
4- & 523.846 & 227 & 0.000 & 0.834 & 0.763 & 0.053 & 0.107 & 7949.173 \\
factor & & & & & & & & \\
5- & $\mathbf{4 3 6 . 7 7 6}$ & $\mathbf{2 0 5}$ & $\mathbf{0 . 0 0 0}$ & $\mathbf{0 . 8 7 1}$ & $\mathbf{0 . 7 9 5}$ & $\mathbf{0 . 0 4 1}$ & $\mathbf{0 . 0 9 9}$ & $\mathbf{7 9 0 6 . 1 0 2}$ \\
factor & & & & & & & & \\
6- & 371.874 & 184 & 0.000 & 0.895 & 0.815 & 0.035 & 0.094 & $\mathbf{7 8 8 3 . 2 0 0}$ \\
factor & & & & & & & & \\
\hline
\end{tabular}




\section{Table 11}

Factor Loadings for Confirmatory Factor Analysis for Motivations for Cyber-social Aggression

Jealousy Revenge Amusement Social Anonymity

Image

1. I thought it would help me get closer to

$.722 *$

one or more other friends

3. I thought it would get me closer to a

$.715 *$

guy/girl I liked

4. I just wanted to be accepted by the group

$.722 \%$

5. I thought it would make me more popular

14. I was jealous about another relationship

that was developing between him/her and

one of my other friends

15. I was jealous of a relationship that was

developing between him/her and a guy/girl

16. I felt insecure about my friendships

$.691 \%$

23. I was envious of something he/she had

24. I was jealous of him/her

$.775 *$

6. I was trying to get back at him/her for something he/she did that made me mad

7. I was angry about something and wanted

to put him/her in his/her place

9. It seemed like a fun thing to do at the time

10. I was bored

11. I didn't have anything better to do

8. I wanted to belong to the 'right' group of friends

18. I wanted to get my point across to $\mathrm{him} /$ her but stay 'looking nice' to the rest of my friends

20. I wanted people to still think I was nice

21. I thought he/she wasn't cool

22. I thought he/she was too emotional

26. I thought it was unlikely that I would get caught 
27. I thought it was unlikely that anyone

would know who did it

$p^{*<.05}$ 


\section{Table 12}

Comparison of Motivations for Motivations for Social Aggression and Motivations for Cyber-social Aggression and which factor they loaded on

Item MSA MCA

1. I thought it would help me get closer to one or more

1

1
other friends

2. I thought one or more of my friends didn't like him/her

3. I thought it would get me closer to a guy/girl I liked

4. I just wanted to be accepted by the group

5. I thought it would make me more popular

8. I wanted to belong to the 'right' group of friends

16. I felt insecure about my friendships

17. I wanted to avoid getting in trouble with adults

20. I wanted people to still think I was nice

6. I was trying to get back at him/her for something he/she

1

1

1

1

1

1

1

1

2

did that made me mad

7. I was angry about something and wanted to put him/her in his/her place

9. It seemed like a fun thing to do at the time

10. I was bored

12. Thought it would be exciting

14. I was jealous about another Relationship that was

developing between him/her and one of my other friends

15. I was jealous of a relationship that was developing between him/her and guy/girl

23. I was envious of something he/she had

24. I was jealous of him/her

25. I thought I would not get in trouble

26. I thought it was unlikely I would get caught

27. I thought it was unlikely anyone would know who did it

13. I thought he/she was going to do something bad to me so I wanted to do something to him/her first

18. I wanted to get point across to him/her but stay 'looking nice' to the rest of my friends

19. I figured it was a socially acceptable way of getting out my anger
Removed

Removed

Removed

4

Removed

Removed 
21. I thought he/she wasn't cool

Removed

4

22. I thought he/she was too emotional

Removed

4

11. I didn't have anything better to do

Removed

3

Similar loadings are bolded 
Table 13

Means, Standard Deviations and Gender Differences for Motivations for Social Aggression and Motivations for Cyber-social Aggression

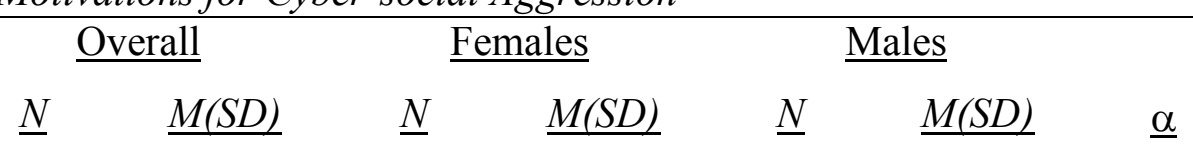

$\underline{\text { MSA }}$

\begin{tabular}{lccccccc} 
Acceptance & $\mathbf{1 3 4}$ & $\mathbf{1 . 5 9}(\mathbf{. 7 7})$ & $\mathbf{8 0}$ & $\mathbf{1 . 7 4}(\mathbf{. 8 7})$ & $\mathbf{5 4}$ & $\mathbf{1 . 3 6}(\mathbf{5 3})$ & $\mathbf{. 8 7}$ \\
Revenge & 134 & $2.83(1.52)$ & 80 & $3.03(1.54)$ & 54 & $2.53(1.46)$ & .80 \\
Amusement & 134 & $1.58(1.00)$ & 80 & $1.48(.95)$ & 54 & $1.73(1.07)$ & .84 \\
Jealousy & $\mathbf{1 3 4}$ & $\mathbf{1 . 4 4 ( . 8 6 )}$ & $\mathbf{8 0}$ & $\mathbf{1 . 6 1 ( . 9 9 )}$ & $\mathbf{5 4}$ & $\mathbf{1 . 1 8}(. \mathbf{5 4})$ & $\mathbf{. 8 6}$ \\
Anonymity & 134 & $1.51(.92)$ & 80 & $1.57(.99)$ & 54 & $1.41(.79)$ & .81 \\
MCA & & & & & & & \\
Jealousy & 90 & $1.52(.80)$ & 59 & $1.61(.84)$ & 31 & $1.35(.69)$ & .92 \\
Revenge & 90 & $2.72(1.49)$ & 59 & $2.85(1.49)$ & 31 & $2.48(.50)$ & .78 \\
Amusement & 90 & $1.72(1.10)$ & 59 & $1.60(1.02)$ & 31 & $1.94(1.22)$ & .88 \\
Social & 90 & $1.69(.91)$ & 59 & $1.76(.99)$ & 31 & $1.56(.74)$ & .85 \\
Image & & & & & & & \\
Anonymity & 90 & $1.59(1.00)$ & 59 & $1.59(1.02)$ & 31 & $1.58(.97)$ & .88 \\
\hline
\end{tabular}

Items in bold indicate significant gender differences $(p<.005)$ 
Appendix A

\section{Principal Consent Form}

\section{Dear Principal,}

The purpose of an informed consent is to ensure that you understand why we are doing this study and what will be expected of students in your school and if you would like to be involved.

Purpose. The consequences of being involved in bullying can be devastating but there is hope. I witnessed this first hand as I was a grade 12 student at Central Kings Rural High School when Pink Shirt Day was established. Cyber aggression is prominent in the media and society today. Recently, there have been some serious incidents of cyberbullying in Nova Scotia as well as Ontario and British Columbia. In response to these events new laws have been put in place to try to help address this issue but if we want to be able to help youth we need to know more about how and why they use these behaviours. It is important that researchers determine the unique aspects of this form of bullying in order to help those being victimized. The purpose of this letter is to ask for your permission for your school to participate in a study being used for a Master's thesis at Carleton University, which will contribute to our knowledge regarding the details of cyber aggression.

What we will ask students to do. Students will be asked to fill out an anonymous questionnaire about their relationships on-and-offline, reactions to certain social situations, and how often they are involved in these types of events. The questionnaires will take about 45 minutes to complete. Filling out the questionnaires will take place at your school during class time.

Potential risk/discomfort. There are no known physical risks to participating in this study. Some students might feel uncomfortable when asked to think about peer conflict. If students feel any discomfort, they may skip questions, and will not be penalized if they do this. At the end of the study, we will provide contact information for local support services that you may contact if you or youth at your school want help dealing with these issues.

Anonymity/Confidentiality. We will not collect any identifying information with your students' surveys, so that their responses can never be traced back to them. Any identifying information that you provide to us (i.e., your name, signature and a way to contact you if you wish to hear about the results of the study) will be confined to a single page that will be kept separate from the questionnaires, secured in a locked research office and will be destroyed after 5 years.

Right to withdraw. Your schools participation in this study is entirely voluntary. At any point during the study, students have the right to not complete certain questions, or to withdraw from the study without penalty. This study has received clearance by the Carleton University Psychology Research Ethics Board (Reference \#00-000). 
Once the study is complete, general group results will be made available to interested parents and school personnel. Your participation is completely voluntary. You have the right to withdraw at any time for any reason. If you should have any questions about the study or your participation in this study, you are welcomed to contact either Dr. Tina Daniels (Associate Professor of Psychology, Carleton University) or myself (Megan Lamb, Master's Candidate, Carleton University). For ethical concerns regarding the study please contact Shelley Brown, (Chair, Carleton University Research Ethics Committee for Psychological Research) at 613-520-2600 ext. 1505. If you have any questions regarding any other aspects of this study you are welcomed to contact Anne Bowker (Chair of the Department of Psychology) at 613-520-2600 ext. 8218

We would like to thank you once again for your participation.

Sincerely, Megan Lamb, Master's Student, Psychology Dept. Carleton University meganlamb@cmail.carleton.ca

Tina Daniels, $\mathrm{PhD}$

Faculty Supervisor, Psychology Dept. Carleton University tina_daniels@carleton.ca 613-520-2600 ext.2686 


\section{Consent Form}

I have read the above description regarding the study on motivations for cyber aggression in adolescents and understand the conditions of my participation. My signature indicates that I agree for (insert name of school) to participate in this study.

Date:

Participant's Name: Signature: 
Appendix B

\section{Teacher Consent Form}

\section{Dear Teacher,}

The purpose of an informed consent is to ensure that you understand why we are doing this study and what will be expected of students in your classroom and if you would like to be involved.

Purpose. The consequences of being involved in bullying can be devastating but there is hope. I witnessed this first hand as I was a grade 12 student at Central Kings Rural High School when Pink Shirt Day was established. Cyber aggression is prominent in the media and society today. Recently, there have been some serious incidents of cyberbullying in Nova Scotia as well as Ontario and British Columbia. In response to these events new laws have been put in place to try to help address this issue but if we want to be able to help youth we need to know more about how and why they use these behaviours. It is important that researchers determine the unique aspects of this form of bullying in order to help those being victimized. The purpose of this letter is to ask for your permission for your classroom to participate in a study being conducted for a Master's thesis at Carleton Unviersity, which will contribute to our knowledge regarding the details of cyber aggression.

What we will ask students to do. Students will be asked to fill out an anonymous questionnaire about their relationships on-and-offline, reactions to certain social situations, and how often they are involved in these types of events. The questionnaires will take about 45 minutes to complete. Filling out the questionnaires will take place at your school during class time. Students without permission will be asked to work quietly in your classroom at work that you have assigned to them.

Potential risk/discomfort. There are no known physical risks to participating in this study. Some students might feel uncomfortable when asked to think about peer conflict. If students feel any discomfort, they may skip questions, and will not be penalized if they do this. At the end of the study, we will provide contact information for local support services that you may contact if you or youth at your school want help dealing with these issues.

Anonymity/Confidentiality. We will not collect any identifying information with your students' surveys, so that their responses can never be traced back to them. Any identifying information that you provide to us (i.e., your name, signature and a way to contact you if you wish to hear about the results of the study) will be confined to a single page that will be kept separate from the questionnaires, secured in a locked research office and will be destroyed after 5 years.

Right to withdraw. Your classrooms participation in this study is entirely voluntary. At any point during the study, students have the right to not complete certain questions, or to withdraw from the study without penalty. This study has received clearance by the Carleton University Psychology Research Ethics Board (Reference \#00-000). 
Once the study is complete, general group results will be made available to interested parents and school personnel. Your participation is completely voluntary. You have the right to withdraw at any time for any reason. If you should have any questions about the study or your participation in this study, you are welcomed to contact either Dr. Tina Daniels (Associate Professor of Psychology, Carleton University) or myself (Megan Lamb, Master's Candidate, Carleton University ). For ethical concerns regarding the study please contact Shelley Brown, (Chair, Carleton University Research Ethics Committee for Psychological Research) at 613-520-2600 ext. 1505. If you have any questions regarding any other aspects of this study you are welcomed to contact Anne Bowker (Chair of the Department of Psychology) at 613-520-2600 ext. 8218 We would like to thank you once again for your participation.

Sincerely,

Megan Lamb, Master’s Student, Psychology Dept. Carleton University meganlamb@cmail.carleton.ca

Tina Daniels, $\mathrm{PhD}$

Faculty Supervisor, Psychology Dept. Carleton University tina_daniels@carleton.ca 613520-2600 ext.2686 


\section{Consent Form}

I have read the above description regarding the study on motivations for cyber aggression in adolescents and understand the conditions of my participation. My signature indicates that I agree to allow 45 minutes of classroom time for students to participate in this study. Date:

Participant's Name: Signature: 
Appendix C

\section{Informed consent form}

\section{Dear Parents/Guardians,}

The purpose of an informed consent is to ensure that you understand why we are doing this study and what will be expected of your child if you would like to be involved.

Purpose. The consequences of being involved in bullying can be devastating but there is hope. I witnessed this first hand as I was a grade 12 student at Central Kings Rural High School when Pink Shirt Day was established. Cyber aggression is prominent in the media and society today. Recently, there have been some serious incidents of cyberbullying in Nova Scotia as well as Ontario and British Columbia. In response to these events new laws have been put in place to try to help address this issue but if we want to be able to help youth we need to know more about how and why they use these behaviours. It is important that researchers determine the unique aspects of this form of bullying in order to help those being victimized. The purpose of this letter is to ask for your permission for your child to participate in a study being used for a Master's thesis, which will contribute to our knowledge regarding the details of cyber aggression.

What we will ask your child to do. Your child will fill out an anonymous questionnaire about relationships on and offline, reactions to certain social situations, and how often they are involved in these types of events. The questionnaires will take about 45 minutes to complete. Filling out the questionnaires will take place at your school during class time.

Potential risk/discomfort. There are no known physical risks to participating in this study. Some people might feel uncomfortable when asked to think about peer conflict. If your child feels any discomfort, she or he may skip questions, and will not be penalized if she or he does this. At the end of the study, we will provide contact information for local support services that you or your child may contact if you want help dealing with these issues.

Anonymity/Confidentiality. We will not collect any identifying information with your child's surveys, so that your child's responses can never be traced back to her/him. Any identifying information that you provide to us (i.e., your name, signature and a way to contact you if you wish to hear about the results of the study) will be confined to a single page that will be kept separate from the questionnaires, secured in a locked research office and will be destroyed after 5 years.

Right to withdraw. Your child's participation in this study is entirely voluntary. At any point during the study, she or he has the right to not complete certain questions, or to withdraw from the study without penalty. This study has received clearance by the Carleton University Psychology Research Ethics Board (Reference \#00-000).

If for any reason should you have any questions about the study or the participation of your child in this study you are welcomed to contact either myself or the people whose contact information is provided. For ethical concerns regarding the study please contact 
Shelley Brown, (Chair, Carleton University Research Ethics Committee for Psychological Research) at 613-520-2600 ext. 1505. If you have any questions regarding any other aspects of this study you are welcomed to contact either Dr. Tina Daniels (Associate Professor of Psychology, Carleton University) or myself (Megan Lamb, Master's Candidate, Carleton University). For ethical concerns regarding the study please contact Shelley Brown, (Chair, Carleton University Research Ethics Committee for Psychological Research) at 613-520-2600 ext. 1505. If you have any questions regarding any other aspects of this study you are welcomed to contact Anne Bowker (Chair of the Department of Psychology) at 613-520-2600 ext. 8218

We would like to thank you once again for your participation.

Sincerely,

Megan Lamb

Master's Student, Psychology Dept. Carleton University meganlamb@cmail.carleton.ca

Tina Daniels, $\mathrm{PhD}$

Faculty Supervisor, Psychology Dept. Carleton University tina_daniels@carleton.ca 613520-2600 ext.2686 


\section{Consent Form}

The information that will be collected for this research project is strictly confidential and is protected under the Municipal Freedom of Information and Privacy Act, 1989.

You have read and understand the request for your son/daughter to participate in this study of cyber aggression in adolescents. Please place a check mark next to the statement that corresponds with your decision.

I give permission for my child to participate in this research project.

I do not give permission for my child to participate in this research project.

Date:

Name of Child:

Name of parent or Guardian: (Please print)

Signature of Parent or Guardian:

Please return the signed consent form to your child's teacher as soon as possible. We thank you greatly for your time.

e-mail (if you wish to receive summary results of this study when it is completed) 


\section{Appendix D}

\section{Assent for Children}

You are being asked to participate in a research study led by Carleton University student Megan Lamb, with her supervisor, Dr. Tina Daniels. Megan, and Dr. Daniels are researchers in the Psychology department at Carleton.

It's very important that you know that even though your parent(s)/guardian(s) have given you permission to participate in the study and fill out the survey, it is your choice whether you want to participate.

The reason we're doing this study is to learn more about how youth behave and the reasons why youth choose to sometimes use unkind behaviours in social situations.

We are asking you to fill out questionnaires that will take about 45 minutes to complete. Questionnaires will ask questions about conflict with your friends and school mates, why you think this conflict happens, and how often you are involved in these types of events.

There are no physical risks to participating in this study. Some of you might feel uncomfortable when asked to think about conflict among your peers. If you feel uncomfortable answering any of the questions, you may choose not to answer specific questions, and you will not be penalized in any way if you choose to do so. At the end of the study we will give you a phone number you can call if you need or want help.

Your responses on the survey can never be traced back to you as your name or any other identifying information will not be collected in this study. It is totally anonymous, so if you wish to participate, please don't write your name anywhere on the questionnaire.

Your participation in this study is entirely voluntary. At any point during the study, you have the right to not complete certain questions, or to withdraw from the study without penalty.

This study has received clearance by the Carleton University Psychology Research Ethics Board (Reference \#00-000). 
Appendix E

\section{Volunteer Script and Information}

\section{Please make sure you have the following materials before you go to the classroom: Materials for each Classroom}

1. Consent forms and Questionnaires

2. Extra consent form to read aloud to participants

3. 2-Large envelopes for parental and student consent

4. Extra pencils

5. Debriefing forms for all participants

6. Envelopes to place completed surveys in.

7. Coloured paper to cover answers if being completed in the classroom.

\section{Procedure}

1. Introduce yourself.

a. Hi my name is , I am helping with a study about adolescent behaviours and relationships. This study is for completion of a Masters degree thesis for Megan Lamb from Carleton University. I have been trained to assist in data collection and I am here to help out. If at anytime you have any questions or concerns please let me know. There are no right or wrong answers and you will not be able to be identified based on your answers. Please be sure not to write your name on your survey. If there are any questions that you are not comfortable answering please skip them and continue on if you like. Your help in this study is much appreciated. It is very important for us to understand adolescent relationships. Please answer all questions as honestly as you can. Only research personnel will see your answers. They will not be available to parents, teachers or Principals.

b. Inform students of the following:

i. What do we mean by a FRIEND?

1. A friend can include anyone in his or her peer group. It can be anyone from a close or best friend to someone whom they may hangout with but may not particularly like.

ii. Will I get in trouble for admitting to any of these behaviours?

1. No! No one will see his or her individual answers. The point is not to see who in particular has done these behaviours. It is to get a better idea of what the most common behaviours are and why they are happening. It is very important that they answer honestly.

iii. Can I circle more than one answer for questions?

1. Most questions ask them to pick one. Make sure to stress that we can only code one answer so they should pick the one that is most appropriate. If they have an explanation or comment they can write it in the margin. 
2. Determine which students have parental consent and ask those who do not to do work quietly (The teacher can assist you in this task).

3. Hand out Consent forms to students with permission.

4. Read consent form aloud. Remind students to keep their eyes on their own paper. This is an individual activity. If they have any questions or concerns to raise their hand and you will help them. Remind them about confidentiality and anonymity. They will not get into any trouble regardless of their answers. It is very important that they answer honestly to every question.

5. Ask students to return consent form to you and those who say yes to participate give him or her a questionnaire.

6. Put all consent forms in the envelope and seal.

7. Collect questionnaires when they are completed and place in an envelope which should then be sealed. Do not leave completed surveys anywhere. Place them in the box allocated by Megan.

8. Give out debriefing form to all participating students. Even if they did not fully complete the questionnaire. Read the debriefing aloud if you have the opportunity.

9. Handout Newsletter about info sessions going on that week.

10. Thank the teacher and students for their time and ask if there are any other questions or concerns.

\section{Things to look for:}

1. Distress. Some students may find the topic of aggression and peer relationships to be upsetting. If you see any students that maybe struggling or upset gently remind them that they do not need to continue with the questionnaire if it is concerning them.

2. Students working together. It is important that the questionnaire if filled out individually. If you see students working together please stress the importance of keeping your eyes on your own paper. You can ask people to move, or space their desk further apart or provide a paper or book to cover completed answers. It is critical that students feel safe in answering honestly. This can only happen when there is no chance of others reading their answers.

3. Questions. It is possible that students may not fully understand some of the questions. Often if they are looking around the room or at another student's answers it is probably because there is a question they do not understand. Remind them that you are there to help. You are not judging their answers. These are behaviours that everyone participates in so there is no reason to feel embarrassed or guilty about one's answers. Remind students to put their hand up if they need help or do not understand a question. It is fine to read the question for them.

\section{Things to know:}

\subsubsection{Anxiety, pain, and embarrassment}


It is expected that the possible risk to youth completing the surveys will be minimal however it is possible that some students may feel uncomfortable when asked to think about peer conflict and their experiences with bullying. If a student reports or appears to be experiencing any discomfort, they may skip questions, and will not be penalized if they do this. Participation in this study may cause some anxiety for those participants who may have used socially aggressive behaviours. Because they are not positive behaviours that are encouraged by parents or other supervising adults, indicating that they use these behaviours may cause some anxiety or feelings of guilt. Although participation in the study is not expected to be more of a risk than what would be encountered on a daily basis (especially as youth may be reflecting on their behaviour by this age anyway), a list of local resources that can provide support and help to any concerned parents or students will be provided after youth have completed their surveys. All youth should receive this information with the debriefing form when they have submitted their completed survey. If youth appear distressed at any time during data collection (i.e. look worried, sad, upset) they should be reminded that they can withdraw without penalty at any time.

\section{Confidentiality and Anonymity}

The present study will not collect any identifying information about participants, so that their responses can never be traced back to them. Please ensure that students know they should not put their name on any of the survey materials.

Any identifying information that is provided by parents or educators (i.e., name, signature and contact information if they wish to hear about the results of the study) should be kept separate from the questionnaires during data collection. Please make sure 
that during survey completion no one is looking at or reading another's answers. You may need to move desks or provide paper to cover answers or set up books as a screen to ensure that each youth has an area to complete their survey in that cannot be seen by others. Please be particularly sensitive to teachers walking around reading survey answers. Remind teachers that answers are confidential and ask them to remain at their desk and to 'complete work of their own. Do this is a polite and respectful manner. I f there are any issues with this suggest they speak with Megan Lamb. Any youth not completing surveys should be encouraged to work on their own or read a book. It may be helpful to have them sit in a separate area of the classroom or go to the library if this is possible, 
Appendix F

Debriefing form

What are we trying to learn in this research?

We're interested in knowing more about your beliefs about relationships and feelings about what makes us act certain ways with friends.

Why is this important to scientists or the general public?

It is important to know why children and youth use social and cyber-social aggression. We don't know much about the reasons why youth are motivated to use social and cybersocial aggression knowing this will be helpful for healthy relationships training.

What are our hypotheses and predictions?

It is expected that youth will use cyber-social aggression for the same reasons they use social aggression. For example, to be accepted by the peer group, for fun, to get revenge, to improved your image or status in the group, and because of jealousy. I think boys and girls will have different reasons for using social aggression and cyber aggression. Girls may be more likely to use the behaviours to increase their acceptance in their group while boys may be more likely to use these behaviours to gain more status and power.

\section{Where can I learn more?}

- PREVNet.ca (The Promoting Relationships and Elimination Violence Network) is a website that has many downloadable resources for parents and teachers.

- www.cyberbullying.us is a website that provides information and resources about cyberbullying for youth, parents, educators and researchers.

- Anti-Bullying Network (http://www.antibullying.net/youngpeople.htm)

- Girls Inc. (http://www.girlsinc.org/)

- Social Aggression Among Girls (2003) by Marion K. Underwood is a popular academic book about social aggression used by girls.

- Odd Girl Out: The Hidden Culture of Aggression in Girls (2002) by Rachel Simmons is a popular and very accessible book about social aggression used by girls.

- Raising Cain: Protecting the Emotional Life of Boys by Dan Kindlon \& Michael

Thompson

- Real Boys: Rescuing Our Sons from the Myths of Boyhood by William Pollack

- The Anger Workbook for Teens: Activities to Help You Deal with Anger and

Frustration by Raychelle Cassada Lohmann

- Don't Let Your Emotions Run Your Life for Teens: Dialectical Behavior Therapy Skills for Helping You Manage Mood Swings, Control Angry Outbursts, and Get Along with Others by Sheri Van Dijk

Is there anything I can do if I found this experiment to be emotionally upsetting? If you found answering these questions upsetting or you need help because to are being targeted by others you should talk to someone you trust. This could be your principal, teacher, parents or a friend. The important thing is to seek help. You can 
call the Kids Help Phone (1-800-668-6868) www.kidshelpphone.ca/ to talk with someone who is trained to help.

- Teens Against Bullying (http://www.pacerteensagainstbullying.org/\#/home)

- Talk to a parent or guardian

\section{What if I have questions later?}

If you have any other concerns, questions, or comments about the experiment, please feel free to contact Megan Lamb (meganlamb@cmail.carleton.ca) or Dr. Tina Daniels (Faculty Sponsor), at: tina_daniels@carleton.ca. If you feel confused or upset about any of the questions asked please talk to a parent or trusted adult. There are a number of resources listed above if you are feeling bad. 
Appendix G

About You (check one):
1. Grade___ Year of birth__ Day _
Gender: Male or Female (circle one)

2. People sometimes think about themselves in terms of nationality, race or the color of their skin. If you feel comfortable identifying yourself in this way, please answer the question below. Check more than one if appropriate. Which statement best describes you:

European-Canadian (White)

$\square$ African/West Indian-Canadian (Black)

Native-Canadian (First Nations, Native Indian, Aboriginal, Metis, Inuit)

$\square$ Asian-Canadian (Chinese, Japanese, Korean, etc.)

$\square$ I don't know

$\square$ Other (please specify) 
1. Please rate the following

\begin{tabular}{|c|c|c|c|c|c|}
\hline & $\stackrel{0}{\stackrel{0}{0}}$ & 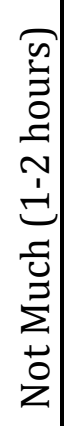 & 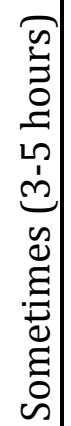 & 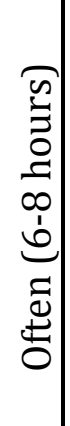 & 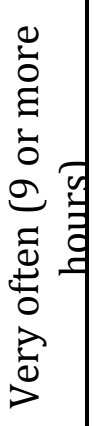 \\
\hline How often do you use the internet at home in a day. & $\mathbf{0}$ & $\mathbf{0}$ & $\mathbf{0}$ & $\mathbf{0}$ & $\mathbf{0}$ \\
\hline How often do you use the internet on your phone in a day. & $\mathbf{O}$ & $\mathbf{0}$ & $\mathbf{0}$ & $\mathbf{0}$ & $\mathbf{0}$ \\
\hline How often do you use the internet at school in a day. & $\mathbf{0}$ & $\mathbf{0}$ & 0 & 0 & $\mathbf{0}$ \\
\hline $\begin{array}{l}\text { How often do you use the internet at a friend's house in a } \\
\text { day }\end{array}$ & $\mathbf{0}$ & $\mathbf{0}$ & 0 & 0 & $\mathbf{0}$ \\
\hline Other & $\mathbf{0}$ & $\mathbf{0}$ & 0 & 0 & $\mathbf{0}$ \\
\hline
\end{tabular}


2. How much do you use the following to communicate with your friends?

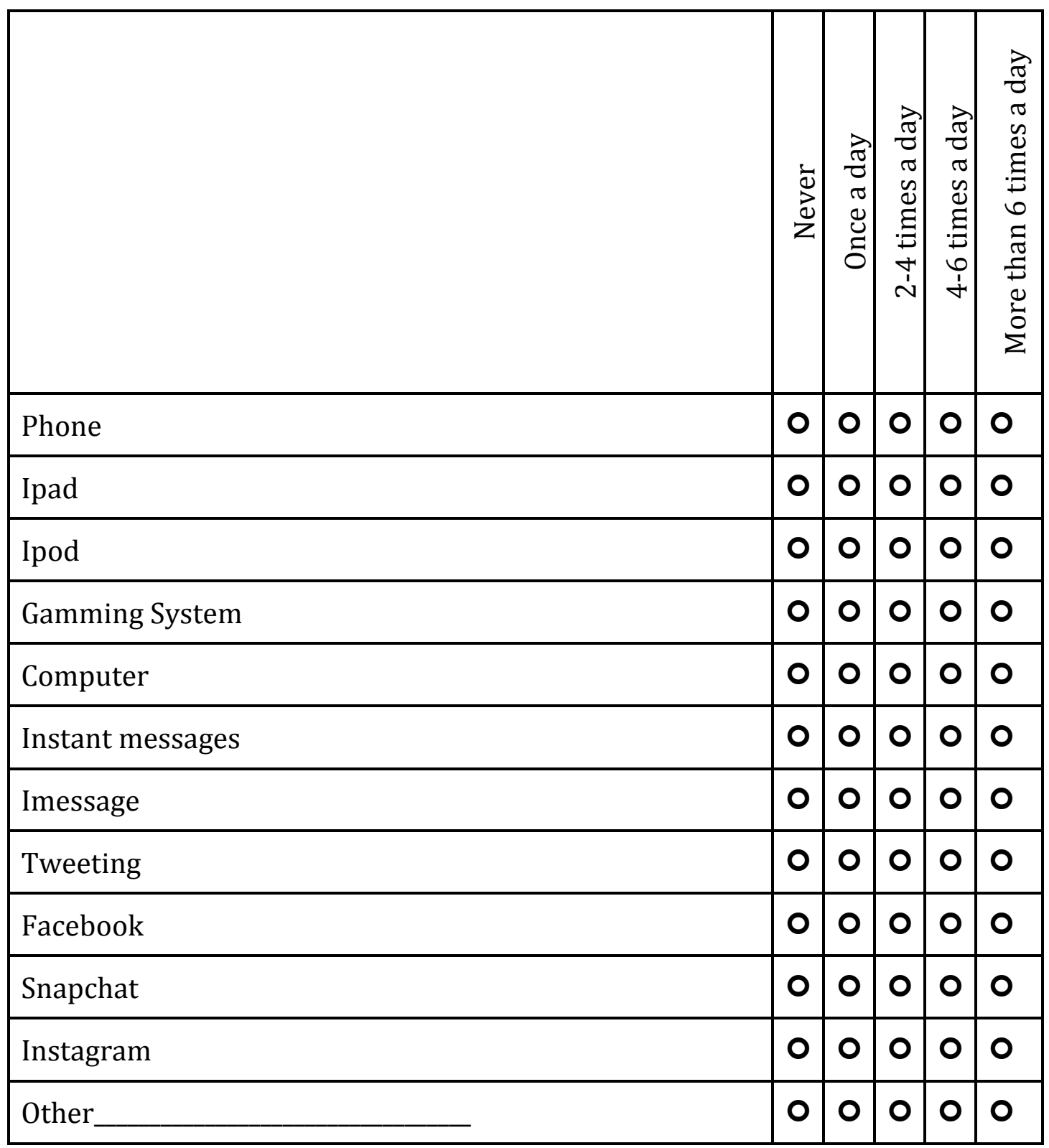

Please rate the following: 


\begin{tabular}{|c|c|c|c|c|c|}
\hline & : & 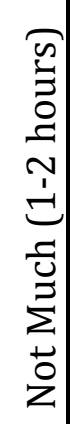 & 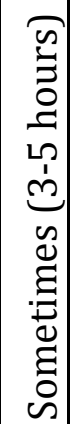 & 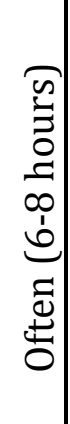 & 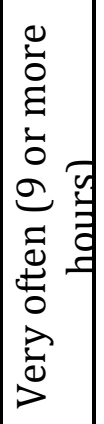 \\
\hline $\begin{array}{l}\text { How much time do you spend on the internet during a } \\
\text { single week day }\end{array}$ & 0 & 0 & 0 & 0 & 0 \\
\hline $\begin{array}{l}\text { How much time do you spend on the internet during a } \\
\text { Saturday or Sunday }\end{array}$ & 0 & 0 & 0 & 0 & 0 \\
\hline
\end{tabular}


1. How often do you use the Internet for the following

\begin{tabular}{|c|c|c|c|c|c|}
\hline & $\begin{array}{l}\dot{d} \\
\stackrel{d}{z} \\
\dot{z}\end{array}$ & $\begin{array}{l}\vec{\sigma} \\
\tilde{\delta} \\
\tilde{D} \\
\tilde{U} \\
\tilde{0}\end{array}$ & 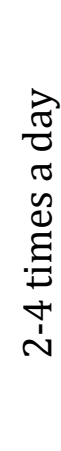 & 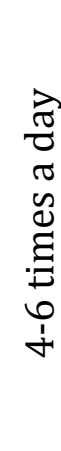 & 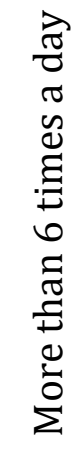 \\
\hline Chat rooms & 0 & 0 & 0 & 0 & 0 \\
\hline Instant messaging & 0 & 0 & 0 & 0 & 0 \\
\hline Email & 0 & 0 & 0 & 0 & 0 \\
\hline School work & 0 & 0 & 0 & 0 & 0 \\
\hline Facebook & 0 & 0 & 0 & 0 & 0 \\
\hline Twitter & 0 & 0 & 0 & 0 & 0 \\
\hline Snapchat & 0 & 0 & 0 & 0 & 0 \\
\hline Instagram & 0 & 0 & 0 & 0 & 0 \\
\hline Online Games & 0 & 0 & 0 & 0 & 0 \\
\hline Shopping & 0 & 0 & 0 & 0 & 0 \\
\hline Other_ & 0 & 0 & 0 & 0 & 0 \\
\hline
\end{tabular}


Appendix $\mathrm{H}$

Frequency of Social Aggression

\section{My Behaviour}

SINCE SCHOOL BEGAN IN THE FALL, how often have you done each of the following to a friend:

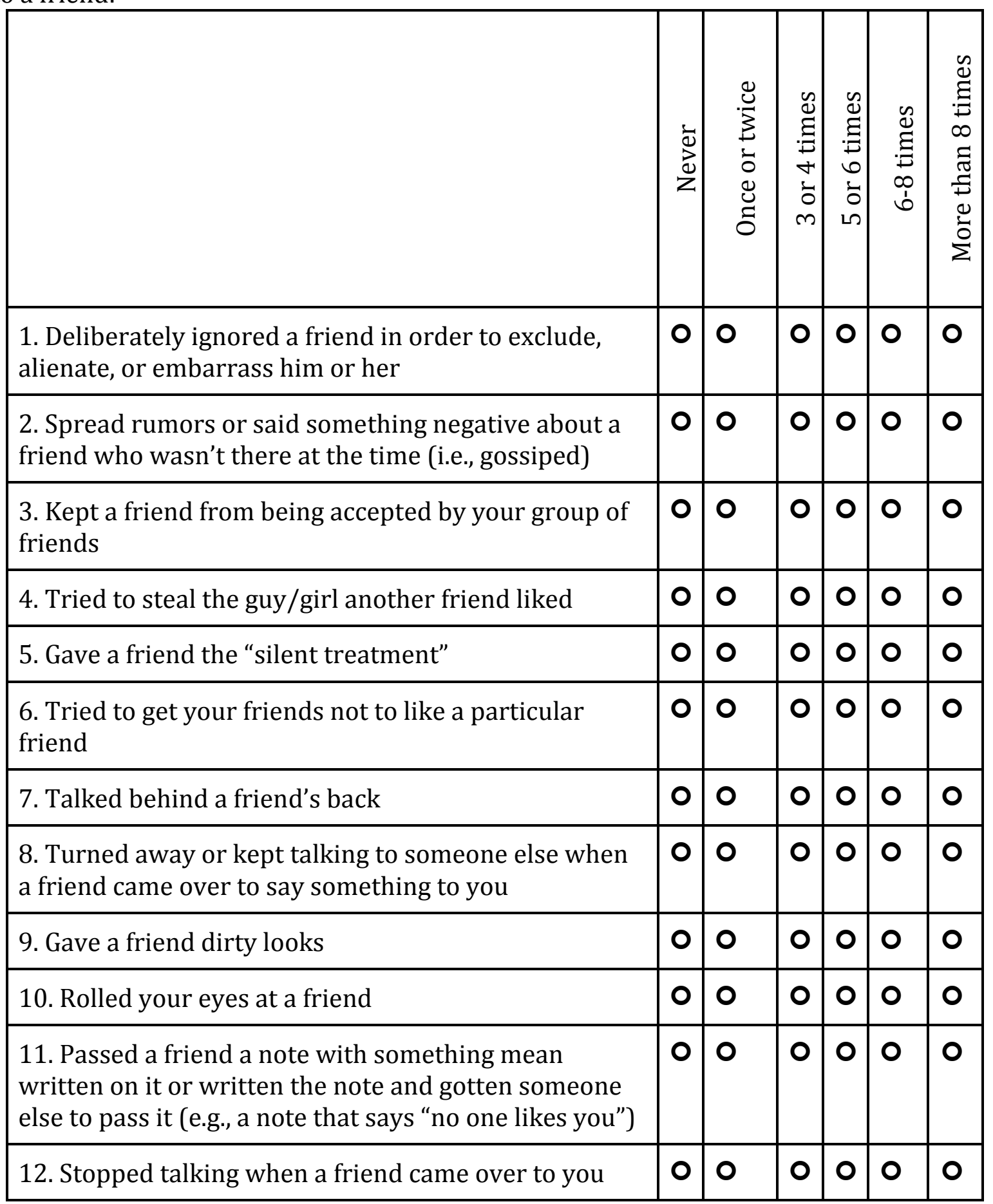




\begin{tabular}{|l|l|l|l|l|l|l|}
\hline and a friend so he or she couldn't join the conversation & & & & & & \\
\hline $\begin{array}{l}\text { 13. Made a mean face when asked to be partners with } \\
\text { a guy/girl for a school project }\end{array}$ & $\mathbf{0}$ & $\mathbf{0}$ & $\mathbf{0}$ & $\mathbf{0}$ & $\mathbf{0}$ & $\mathbf{0}$ \\
\hline 14. Glared or stared at a guy/girl meanly & $\mathbf{0}$ & $\mathbf{0}$ & $\mathbf{0}$ & $\mathbf{0}$ & $\mathbf{0}$ & $\mathbf{0}$ \\
\hline $\begin{array}{l}\text { 15. Didn't invite a friend to a party to be hurtful even } \\
\text { though you knew he/she wanted to come }\end{array}$ & $\mathbf{0}$ & $\mathbf{0}$ & $\mathbf{0}$ & $\mathbf{0}$ & $\mathbf{0}$ & $\mathbf{0}$ \\
\hline
\end{tabular}

How serious do you feel these behaviours are?

nnot at all serious

slightly serious

_not sure

somewhat serious

_very serious 


\section{Friend's Behaviour}

SINCE SCHOOL BEGAN IN THE FALL, how often has this been done to you by a friend:

\begin{tabular}{|c|c|c|c|c|c|c|}
\hline & $\begin{array}{l}\grave{0} \\
\grave{0} \\
z\end{array}$ & 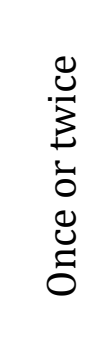 & $\begin{array}{l}\mathscr{y} \\
\stackrel{\Xi}{\Xi} \\
\stackrel{+}{+} \\
\overleftarrow{0} \\
m\end{array}$ & 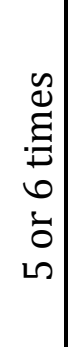 & $\begin{array}{l}\mathscr{d} \\
\stackrel{\Xi}{\Xi} \\
\infty \\
\vdots \\
b\end{array}$ & 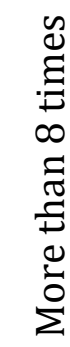 \\
\hline $\begin{array}{l}\text { 1. A friend has deliberately ignored me because she } \\
\text { was trying to exclude, alienate, or embarrass me }\end{array}$ & 0 & 0 & 0 & 0 & 0 & 0 \\
\hline $\begin{array}{l}\text { 2. A friend has spread rumors or said something } \\
\text { negative about me behind my back (i.e., gossiped) }\end{array}$ & 0 & 0 & 0 & 0 & 0 & 0 \\
\hline $\begin{array}{l}\text { 3. A friend wouldn't accept me in their group of } \\
\text { friends }\end{array}$ & 0 & 0 & 0 & 0 & 0 & 0 \\
\hline 4. A friend has tried to steal the guy/girl I liked & 0 & 0 & 0 & 0 & 0 & 0 \\
\hline 5. A friend has given me the "silent treatment" & 0 & 0 & 0 & 0 & 0 & 0 \\
\hline $\begin{array}{l}\text { 6. A friend has tried to get another friend not to like } \\
\text { me. }\end{array}$ & 0 & 0 & 0 & 0 & 0 & 0 \\
\hline 7. A friend has talked behind my back & 0 & 0 & 0 & 0 & 0 & 0 \\
\hline $\begin{array}{l}\text { 8. A friend has turned away or kept talking to } \\
\text { someone else when I came over to say something to } \\
\text { him/her }\end{array}$ & 0 & 0 & 0 & 0 & 0 & 0 \\
\hline 9. A friend has given me dirty looks & 0 & 0 & 0 & 0 & 0 & 0 \\
\hline 10. A friend has rolled his or her eyes at me & 0 & 0 & 0 & 0 & 0 & 0 \\
\hline $\begin{array}{l}\text { 11. A friend has passed me a note with something } \\
\text { mean written on it or written the note and gotten } \\
\text { someone else to pass it (e.g., a note that says "no one } \\
\text { likes you") }\end{array}$ & 0 & 0 & 0 & 0 & 0 & 0 \\
\hline $\begin{array}{l}\text { 12. A friend stopped talking when I came over so I } \\
\text { couldn't join the conversation }\end{array}$ & 0 & 0 & 0 & 0 & 0 & 0 \\
\hline
\end{tabular}




\begin{tabular}{|l|l|l|l|l|l|l|}
\hline $\begin{array}{l}\text { 13. A friend has made a mean face when asked to be } \\
\text { partners with me for a school project }\end{array}$ & $\mathbf{0}$ & $\mathbf{0}$ & $\mathbf{0}$ & $\mathbf{0}$ & $\mathbf{0}$ & $\mathbf{0}$ \\
\hline 14. A friend has glared or stared at me meanly & $\mathbf{0}$ & $\mathbf{0}$ & $\mathbf{0}$ & $\mathbf{0}$ & $\mathbf{0}$ & $\mathbf{0}$ \\
\hline $\begin{array}{l}\text { 15. A friend didn't invite me to a party even though } \\
\text { they knew I wanted to come to be hurtful }\end{array}$ & $\mathbf{0}$ & $\mathbf{0}$ & $\mathbf{0}$ & $\mathbf{0}$ & $\mathbf{0}$ & $\mathbf{0}$ \\
\hline
\end{tabular}

Please indicate how you know the person who used these behaviours toward you: Is he or she A friend (in your friend group) Non friend (outside of your friend group)

How long have you known this person? 


\section{Appendix I}

Frequency of Cyber-social Aggression

\section{My Behaviour}

SINCE SCHOOL BEGAN IN THE FALL, how often have you done each of the following to a friend:

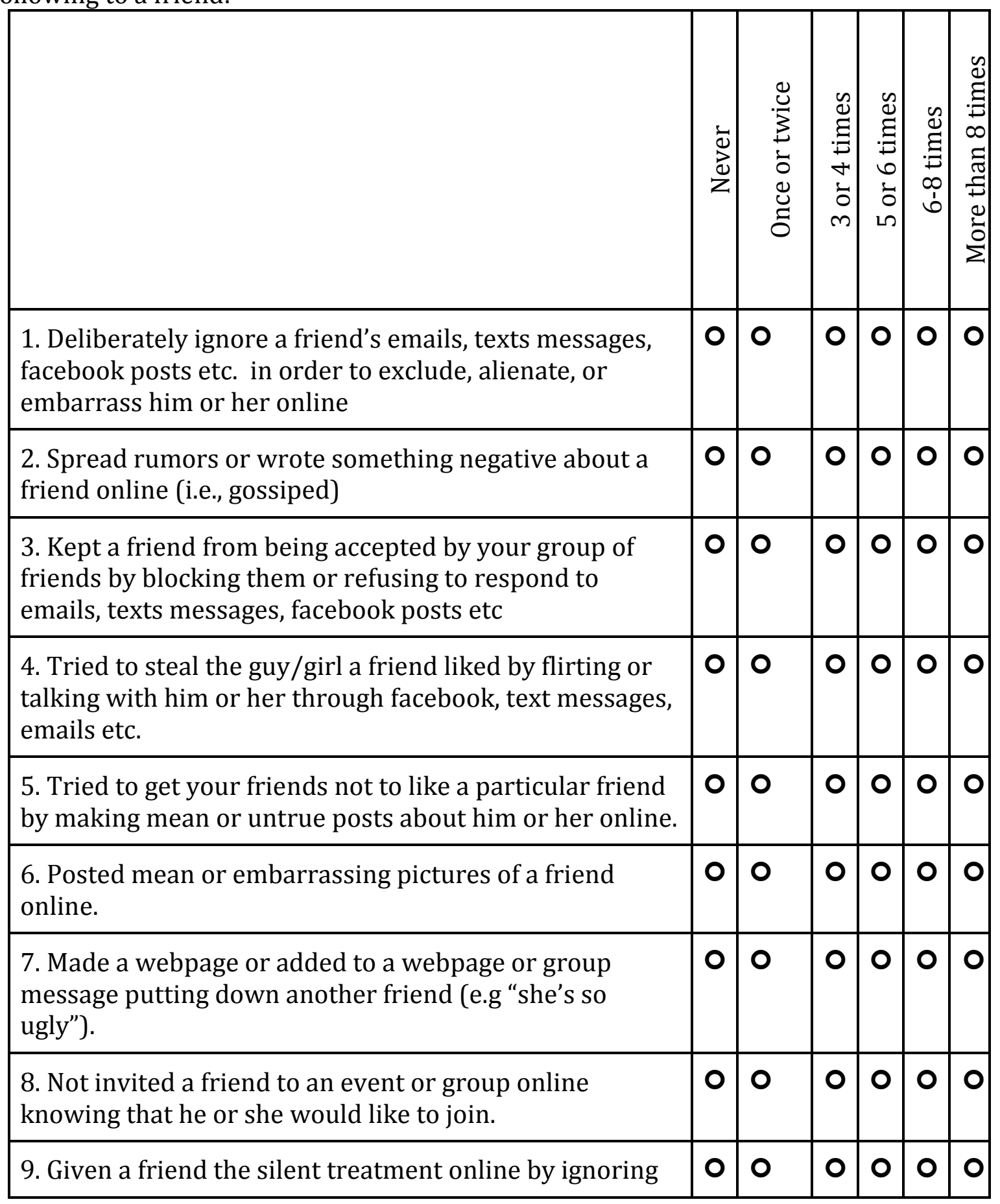




\begin{tabular}{|c|c|c|c|c|c|c|}
\hline his or her messages. & & & & & & \\
\hline $\begin{array}{l}\text { 10. Sent mean, hostile, or intimidating messages to a } \\
\text { friend online. }\end{array}$ & 0 & 0 & 0 & 0 & 0 & 0 \\
\hline 11. Told a friend you did not like him or her online. & 0 & $\mathbf{0}$ & $\mathbf{0}$ & $\mathbf{0}$ & $\mathbf{0}$ & $\mathbf{0}$ \\
\hline $\begin{array}{l}\text { 12. Pretended to be a friend online to embarrass him or } \\
\text { her }\end{array}$ & 0 & 0 & 0 & 0 & 0 & 0 \\
\hline $\begin{array}{l}\text { 13. Tricked a friend into sharing personal information } \\
\text { that you could use against him or her through email, } \\
\text { chatrooms etc.. }\end{array}$ & 0 & 0 & 0 & 0 & 0 & 0 \\
\hline $\begin{array}{l}\text { 14. Shared a friend's personal information to embarrass } \\
\text { him or her on line. }\end{array}$ & 0 & $\mathbf{0}$ & 0 & 0 & $\mathbf{0}$ & $\mathbf{0}$ \\
\hline $\begin{array}{l}\text { 15. Told a friend's secret online to publically embarrass } \\
\text { him or her. }\end{array}$ & 0 & 0 & 0 & 0 & 0 & 0 \\
\hline
\end{tabular}

How serious do you feel these behaviours are? not at all serious slightly serious not sure somewhat serious very serious 


\section{Friend's Behaviour}

SINCE SCHOOL BEGAN IN THE FALL, how often has this been done to you by a friend:

\begin{tabular}{|c|c|c|c|c|c|c|}
\hline & $\begin{array}{c}\grave{d} \\
\grave{d} \\
z\end{array}$ & 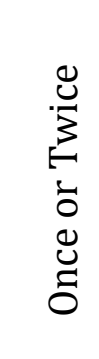 & 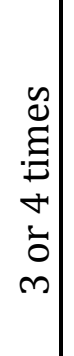 & 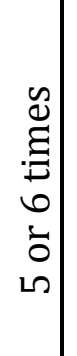 & $\begin{array}{l}\mathscr{Q} \\
\stackrel{\Xi}{\Xi} \\
\infty \\
\infty \\
1\end{array}$ & 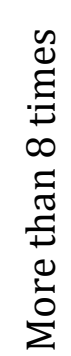 \\
\hline $\begin{array}{l}\text { 1. A friend has deliberately ignored my emails, texts } \\
\text { messages, facebook posts etc. in order to exclude, } \\
\text { alienate, or embarrass me }\end{array}$ & 0 & 0 & 0 & 0 & 0 & 0 \\
\hline $\begin{array}{l}\text { 2. A friend has spread rumors or wrote something } \\
\text { negative about me online (i.e., gossiped) }\end{array}$ & 0 & 0 & 0 & 0 & 0 & 0 \\
\hline $\begin{array}{l}\text { 3. A friend kept me from being accepted by a group of } \\
\text { friends by blocking me or refusing to respond to emails, } \\
\text { texts messages, facebook posts etc }\end{array}$ & 0 & 0 & 0 & 0 & 0 & 0 \\
\hline $\begin{array}{l}\text { 4. A friend tried to steal the guy/girl I liked by flirting or } \\
\text { talking with them through facebook, text messages, } \\
\text { emails etc. }\end{array}$ & 0 & 0 & 0 & 0 & 0 & 0 \\
\hline $\begin{array}{l}\text { 5. A friend tried to get his or her friends not to like me } \\
\text { by making mean or untrue posts about me. }\end{array}$ & 0 & 0 & 0 & 0 & 0 & 0 \\
\hline $\begin{array}{l}\text { 6. A friend posted mean or embarrassing pictures of me } \\
\text { online. }\end{array}$ & 0 & 0 & 0 & 0 & 0 & 0 \\
\hline $\begin{array}{l}\text { 7. A friend made or added to a webpage or group } \\
\text { message putting me down (e.g "she's so ugly"). }\end{array}$ & 0 & 0 & 0 & 0 & 0 & 0 \\
\hline $\begin{array}{l}\text { 8. A friend didn't invite me to an event or group online } \\
\text { knowing that I would like to join. }\end{array}$ & 0 & 0 & 0 & 0 & 0 & 0 \\
\hline $\begin{array}{l}\text { 9. A friend gave me the silent treatment online by } \\
\text { ignoring my messages. }\end{array}$ & 0 & 0 & 0 & 0 & 0 & 0 \\
\hline $\begin{array}{l}\text { 10. A friend sent me mean, hostile, or intimidating } \\
\text { messages online. }\end{array}$ & 0 & 0 & 0 & 0 & 0 & 0 \\
\hline
\end{tabular}




\begin{tabular}{|l|l|l|l|l|l|l|}
\hline 11. A friend told me he /she did not like me online. & $\mathbf{0}$ & $\mathbf{0}$ & $\mathbf{0}$ & $\mathbf{0}$ & $\mathbf{0}$ & $\mathbf{0}$ \\
\hline 12. A friend pretended to be me online to embarrass me. & $\mathbf{0}$ & $\mathbf{0}$ & $\mathbf{0}$ & $\mathbf{0}$ & $\mathbf{0}$ & $\mathbf{0}$ \\
\hline $\begin{array}{l}\text { 13. A friend tricked me into sharing personal } \\
\text { information that he/she could use against me online. }\end{array}$ & $\mathbf{0}$ & $\mathbf{0}$ & $\mathbf{0}$ & $\mathbf{0}$ & $\mathbf{0}$ & $\mathbf{0}$ \\
\hline $\begin{array}{l}\text { 14. A friend shared my personal information to } \\
\text { embarrass me online. }\end{array}$ & $\mathbf{0}$ & $\mathbf{0}$ & $\mathbf{0}$ & $\mathbf{0}$ & $\mathbf{0}$ & $\mathbf{0}$ \\
\hline $\begin{array}{l}\text { 15. A friend told a secret I had online to publically } \\
\text { embarrass me. }\end{array}$ & $\mathbf{0}$ & $\mathbf{0}$ & $\mathbf{0}$ & $\mathbf{0}$ & $\mathbf{0}$ & $\mathbf{0}$ \\
\hline
\end{tabular}

Please indicate how you know the person who used these behaviours toward you: Is he or she A friend (in your friend group)

_ Non friend (outside of your friend group)

How long have you known this person? 


\section{Appendix J}

Motivations for Social Aggression

\section{My Experience}

Social Aggression refers to the use of relationships as weapons to hurt others. This can include spreading mean rumours about someone so others will not like them, leaving others out on purpose to be hurtful.

Think about one memorable time (SINCE SCHOOL BEGAN IN THE FALL) when you did something that was described above and briefly describe it below. This is only to help you remember the incident, so write whatever you need to help you remember it. If you can remember, write down who was involved including whether they were boys or girls, what happened, how long it lasted, and how things are now. To ensure this survey is anonymous, please don't write down anyone's name.

Please report the following:

Did this happen with a guy or a girl?

Was this person a friend, some I knew from my group of friends but not a close friend or someone I was vaguely acquainted with? 
Which of these is closest to what you described? Please only choose one.

1. Ignored a guy/girl with the intention of excluding, alienating, or embarrassing her

2. Spread rumors or said something negative about a guy/girl who wasn't there at the time (i.e., gossiped)

3. Kept a guy/girl from being accepted by your group of friends

4. Tried to steal the guy/girl another girl/guy liked

5. Gave a girl/guy the silent treatment

6. Tried to get others not to like a particular girl/guy

7. Talked behind a girl/guy's back

8. Turned away and kept talking to someone else when a girl/guy came over to say something to you

9. Gave a girl/guy dirty looks

10. Rolled your eyes at a girl/guy

11. Passed a girl/guy a mean note (e.g., that says "no one likes you")

12. Stopped talking when a girl/guy came over to you and a friend so she/he couldn't join the conversation

13. Made a mean face when partnered with a girl/guy in class

14. Glared at a girl/guy

15. Not invited a girl/guy to a party or event you knew she'd/he'd want to come to

16. Other

Describe: 


\section{Reasons for the Social Aggression}

\section{Why I did what I did}

There are many reasons why a guy/girl would do any of those things. To understand why people do these things, next we would like you to think about the behaviour that you mentioned above and rate how much you agree that any of the following reasons that explain why you did what you did by checking the boxes.

1. I thought it would help me get closer to one or more other friends

2. I thought one or more of my friends didn't like him/her

3. I thought it would get me closer to a guy/girl I liked

4. I just wanted to be accepted by the group

5. I thought it would make me more popular

6. I was trying to get back at him/her for something he/she did that made me mad

7. I was angry about something and wanted to put him/her in his/her place

8. I wanted to belong to the 'right' group of friends

9. It seemed like a fun thing to do at the time

10. I was bored

11. I didn't have anything better to do

12. I thought it would be exciting

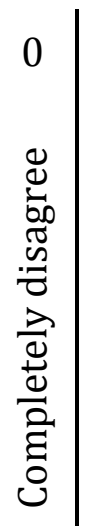


13. I thought he/she was going to do something bad to me so I wanted to do something to him/her first

14. I was jealous about another relationship that was developing between him/her and one of my other friends

15. I was jealous of a relationship that was developing between him/her and a girl/guy

16. I felt insecure about my friendships

17. I wanted to avoid getting in trouble with adults

18. I wanted to get my point across to him/her but stay 'looking nice' to the rest of my friends

19. I figured it was a socially acceptable way of getting out my anger

20. I wanted people to still think I was nice

21. I thought he/she wasn't cool

22. I thought he/she was too emotional

23. I was envious of something he/she had

24. I was jealous of him/her

25. I knew I would not get in trouble

26. I knew he or she would not confront me about my behaviour

27. I knew no one would detect my identity (anonymous)

28. Were there any other reasons you did the behaviour that you described? If so, please list them below and rate how important they were:

Note: Items 1, 2, 6, 9, and 13 are from the original measure by Reynolds and Repetti (2010). 
Appendix K

Motivations for Cyber-social Aggression

\section{My Experience}

Cyber aggression is when someone uses technology such as cell phone, website, instant messages, gaming devices, or social networking sites to hurt another person's feelings or relationships. Cyber aggression may include: posting mean or embarrassing pictures of someone online; making mean comments about another person via Facebook, Twitter, Instagram etc.; spreading rumours about someone online; or deliberating ignoring someone using technology.

Think about one memorable time (SINCE SCHOOL BEGAN IN THE FALL) when you did something that was described above and briefly describe it below. This is only to help you remember the incident, so write whatever you need to help you remember it. If you can remember, write down who was involved including whether they were boys or girls, what happened, how long it lasted, and how things are now. To ensure this survey is anonymous, please don't write down anyone's name.

Please report the following:

Did this happen with a guy or a girl?

Was this person a friend, some I knew from my group of friends but not a close friend or someone I was vaguely acquainted with? 
Which of these is closest to what you described? Please only choose one.

1. Used technology to spread hurtful lies about an individual.

2. Pretended to be someone else online to convince a vulnerable person to give up information about him or herself that you could use against him or her later.

3. Pretended to be someone else online to torment others and avoid getting into trouble.

4. Shared personal information about someone without the person's approval to embarrass or harm the person

5. Trick someone into sharing personal information and then using that information to hurt or embarrass the individual.

6. Leaving someone out on purpose using technology.

7. Leaving someone out of a group on purpose and making him or her aware that he or she is not included online.

8. Sending hostile, aggressive, intimidating, insulting, or sarcastic messages that may include hurtful language to someone online.

9. Sent or forwarded a mean or embarrassing comment about another person online.

$\square \quad$ 10. Not invited a girl/guy to a party or event you knew she'd/he'd want to come to

11. Other 


\section{Why I did what I did}

There are many reasons why a friend would do any of the behaviours above. To understand why people do these things, next we would like you to think about the time you mentioned above and then rate_how much you agree that any of the following reasons explain your choices of what you did by filling in one of the circles.

\begin{tabular}{|c|c|c|c|c|c|}
\hline & 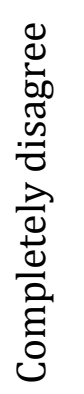 & 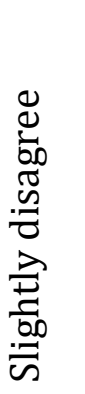 & 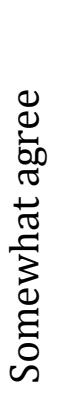 & 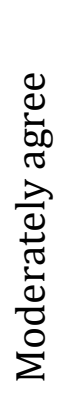 & 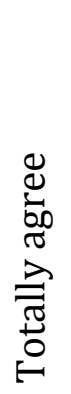 \\
\hline $\begin{array}{l}\text { 1. I thought it would help me get closer to one or } \\
\text { more friends }\end{array}$ & $\mathbf{0}$ & $\mathbf{0}$ & $\mathbf{0}$ & $\mathbf{0}$ & $\mathbf{0}$ \\
\hline $\begin{array}{l}\text { 2. I thought one or more of my friends didn't like } \\
\text { him or her }\end{array}$ & 0 & 0 & 0 & 0 & 0 \\
\hline $\begin{array}{l}\text { 3. I thought it would get me closer to a guy/girl I } \\
\text { liked }\end{array}$ & $\mathbf{0}$ & 0 & $\mathbf{0}$ & $\mathbf{0}$ & 0 \\
\hline 4. I just wanted to be accepted by the group & 0 & 0 & $\mathbf{0}$ & $\mathbf{0}$ & 0 \\
\hline 5. I thought it would make me more popular & $\mathbf{0}$ & 0 & $\mathbf{0}$ & $\mathbf{0}$ & $\mathbf{0}$ \\
\hline $\begin{array}{l}\text { 6. I was trying to get back at him or her for } \\
\text { something he or she did that made me mad }\end{array}$ & 0 & 0 & 0 & 0 & $\mathbf{0}$ \\
\hline $\begin{array}{l}\text { 7. I was angry about something and wanted to } \\
\text { put him or her in his or her place }\end{array}$ & $\mathbf{0}$ & 0 & $\mathbf{0}$ & $\mathbf{0}$ & 0 \\
\hline $\begin{array}{l}\text { 8. I wanted to belong to the 'right' group of } \\
\text { friends }\end{array}$ & $\mathbf{0}$ & $\mathbf{0}$ & $\mathbf{0}$ & $\mathbf{0}$ & 0 \\
\hline 9. It seemed like a fun thing to do at the time & $\mathbf{0}$ & 0 & $\mathbf{0}$ & $\mathbf{0}$ & $\mathbf{0}$ \\
\hline 10. I was bored & $\mathbf{0}$ & 0 & $\mathbf{0}$ & $\mathbf{0}$ & 0 \\
\hline 11. I didn't have anything better to do & $\mathbf{0}$ & 0 & $\mathbf{0}$ & 0 & $\mathbf{0}$ \\
\hline 12. I thought it would be exciting & 0 & 0 & 0 & 0 & 0 \\
\hline 13. I thought he or she was going to do & 0 & 0 & 0 & 0 & 0 \\
\hline
\end{tabular}




\begin{tabular}{|c|c|c|c|c|c|}
\hline $\begin{array}{l}\text { something bad to me so I wanted to do } \\
\text { something to him or her first }\end{array}$ & & & & & \\
\hline $\begin{array}{l}\text { 14. I was jealous about another relationship that } \\
\text { was developing between him or her and one of } \\
\text { my friends }\end{array}$ & $\mathbf{0}$ & 0 & 0 & $\mathbf{O}$ & $\mathbf{0}$ \\
\hline $\begin{array}{l}\text { 15. I was jealous of a romantic relationship that } \\
\text { was developing between him or her and another } \\
\text { friend }\end{array}$ & O & 0 & 0 & $\mathbf{0}$ & $\mathbf{0}$ \\
\hline 16. I felt insecure about my friendships & 0 & 0 & 0 & 0 & 0 \\
\hline $\begin{array}{l}\text { 17. I wanted to avoid getting in trouble with } \\
\text { adults }\end{array}$ & 0 & 0 & 0 & 0 & 0 \\
\hline $\begin{array}{l}\text { 18. I wanted to get my point across to him or her } \\
\text { but stay 'looking nice' to the rest of my friends }\end{array}$ & 0 & 0 & 0 & 0 & 0 \\
\hline $\begin{array}{l}\text { 19. I figured it was a socially acceptable way of } \\
\text { getting out my anger }\end{array}$ & $\mathbf{0}$ & 0 & 0 & 0 & 0 \\
\hline 20. I wanted people to still think I was nice & $\mathbf{0}$ & $\mathbf{0}$ & 0 & 0 & $\mathbf{0}$ \\
\hline 21. I thought he or she wasn't cool & 0 & 0 & 0 & 0 & 0 \\
\hline 22. I thought he or she was too emotional & $\mathbf{0}$ & $\mathbf{0}$ & $\mathbf{0}$ & $\mathbf{O}$ & $\mathbf{0}$ \\
\hline 23. I was envious of something he or she had & $\mathbf{0}$ & $\mathbf{0}$ & $\mathbf{0}$ & $\mathbf{O}$ & $\mathbf{0}$ \\
\hline 24. I was jealous of him or her & 0 & 0 & 0 & 0 & 0 \\
\hline 25. I knew I would not get into trouble & 0 & 0 & 0 & 0 & 0 \\
\hline $\begin{array}{l}26 . \text { I knew he or she would not confront be about } \\
\text { my behaviour }\end{array}$ & 0 & 0 & 0 & 0 & 0 \\
\hline $\begin{array}{l}\text { 27. I knew no one would detect my identity } \\
\text { (anonymous) }\end{array}$ & 0 & 0 & 0 & 0 & 0 \\
\hline $\begin{array}{l}\text { 28. Were there any other reasons you did the } \\
\text { behaviour described above? If so, please list } \\
\text { them below and rate how important they were: }\end{array}$ & 0 & 0 & 0 & 0 & 0 \\
\hline
\end{tabular}

Note: Items 1, 2, 6, 9, and 13 are from the original measure by Reynolds and Repetti (2010). 


\section{Appendix L}

\section{Reasons for removing MSA items}

Two items were removed as they did not load highly on any of the factors (I thought he/she was going to do something bad to me so I wanted to do something to him/her first (13), and I figured it was a socially acceptable way of getting out my anger (18)). In addition, three items were removed due to low loadings on a number of factors; indicating that these items were not clear to participants (I wanted to get my point across to him/her but stay 'looking nice' to the rest of my friends (19), I thought he/she wasn't cool (21), and I thought he/she was too emotional (22)). More specifically, Item 13 (I thought he/she was going to do something bad to me so I wanted to do something to him/her first) was removed as it consistently had moderately low loadings on a number of factors over a number of factor structures. The ambiguity of this item seemed to confuse participants and did not properly measure the underlying construct of revenge. Item 19 ( I wanted to get my point across to him/her but stay 'looking nice' to the rest of my friends ) had high loadings on two factors. Therefore, it was unclear where this item should belong. In addition, participants found the wording consistently confusing. Item 18 (I figured it was a socially acceptable way of getting out my anger) was removed due to equally low factor loadings on three or more items. This was present in many of the factor structures. The final two items that were removed 21 ( $I$ thought he/she wasn't cool) and 22 (I thought he/she was too emotional) were removed due to low factor loadings on two factors across factor structures including three to six factors. 


\section{Appendix M}

\section{Reasons for removing MCA items}

Three items were removed due to approximately equal loadings on two or more factors: I thought one or more of my friends didn't like him or her (2), I thought he/she was going to do something bad to me so I wanted to do something to him/her first (13), and I wanted to avoid trouble with adults (17). In addition, the following item was removed due to low non-significant loadings on all factors; indicating that this item was not associated with any of the factors: I figured it was a socially acceptable way of getting out my anger (19). More specifically, I thought one or more of my friends didn't like him or her (2) was removed as it consistently had moderate loadings on two factors over a number of factor structures. The ambiguity of this item seemed to confuse participants and not properly measure the underlying construct of acceptance.

The I thought he/she was going to do something bad to me so I wanted to do something to him/her first (13) item had low loadings on three or more factors. Therefore, it was unclear where this item should belong. In addition, participants found the wording consistently confusing. The I wanted to avoid trouble with adults (17) item was removed due to equally low factor loadings on three or more items. This was present in many of the factor structures. The final item that was removed I figured it was a socially acceptable way of getting out my anger(19) was removed due to low non significant factor loadings on all factors. 